\title{
Sea Level Damage Risk with Probabilistic Weighting of IPCC Scenarios: An Application to Major Coastal Cities
}

\author{
Luis M. Abadie ${ }^{1, *}$ \\ ${ }^{1}$ Basque Centre for Climate Change (BC3) \\ Edificio Sede Eraikina no.1, 1 | UPV/EHU Parque científico (“Science Park") \\ $\mathrm{B}^{\circ}$ Sarriena s/n, | 48940 Leioa (Spain) \\ E-mail: 1m.abadie@bc3research.org
}

\begin{abstract}
In some coastal cities there is an urgent need to decide on adaptation investments given the long periods needed to complete the relevant infrastructures. However such decisions are usually made under significant uncertainty due to local climate change and socio-economic imnact The Intergovernmental Panel on Climate Change (IPCC) has developed four global scmarios ccording to different representative concentration pathways (RCPs); however, using these cena ios d ectly is equivalent to using incomplete information in the decision-making process berme do not provide information on what sea level rise behavior is most probable. In this st dy, I bro ose a model which assigns probabilities to IPCC scenarios with Local Sea Leve' Rise (L I D ) information. I obtain expected damage and risk measures for the world's 120 major bastal $\mathrm{m}$ ga-cities at specific moments in time. That is, I consider uncertainty in both scenario selection. $\mathrm{d}$ wi in each scenario. With this information it is possible to make adaptation investment decisio s under uncertainty with a criterion of not exceeding certain risk levels in the future. The paper shows at in the year 2100 for the equal probability mixed scenario (25\% RCP 2.6, 50\% RCP 4.5 and 25 凡 8 . ) the expected damage is US\$1,251,732 millions for New Orleans and US\$1,196,517 million for (uangzhou. The risk measurements show that in that year the damage in the 5\% of wor a a w w uS $\$ 2,800,756$ millions for Guangzhou and US\$ $1,832,466$ millions for New Orles ' n , owevi, not all countries have sufficient resources to make the necessary adaptation investments, s we nalyze expected damage and risk according to World Bank country income groups. The pape shows that the USA and China will need to make major adaptation investments in the future. The oast MSLR risk in lower-income cities is also calculated.
\end{abstract}

\section{Key words}

Adaptation, stochastic modeling, climate change, risk measure, uncertainty, country income groups 


\section{Introduction}

In this century coastal cities are being exposed to significant damage from sea level rise (SLR) caused by climate change. This damage may be exacerbated by socio-economic effects such as population and asset growth in those cities (Hallegatte et al 2013). IPCC (IPCC, 2014) global sea level rise (GSLR) information is insufficient because impact effects are not uniform and may affect cities differently as a result of the net contribution of several factors (Kopp et al. 2014). Differences in local sea level rise (LSLR) between cities can be significant, so it is critical for decision-making to work with regionalized data.

The aggregation of negative SLR effects and high-growth socio-economic effects generates the greatest risks, and those risks are increasing over time (Abadie et al., 2107).

Estimations of expected LSLR and the corresponding damage clearly suffer from insufficient information for financial decision-making because of the absence of probabilities assigned to the Representative Concentration Pathway (RCP) scenarios.

In financial economics expected value is not an adequate risk measure (Hull, 2012) (Wilmott, 2014). Risk measures are associated with worst-case events. In this paper we use Expected Shortfall (ES) ${ }^{1}$ as a risk measure. This is a mean value of the worst damage cases which has bettei properties than other risk measures such as Value at Risk (Hull, 2012) (Rockafellar and Uryasev, 2002).

A recent editorial in Nature Climate Change reminds us that specia an ntion should be paid to the socio-economic impacts of significant but less likely climate ever s (E itori., 2016). These lowprobability, high-damage impacts have frequently been discuss at ear climate change economics literature (Weitzman, 2007, 2009, 2013; Nordhaus, 2011 an are yery important due to the huge magnitude of the potential damage from them (Pindycl, 2011). Hminel et al. (2015) also argue in favor of providing estimates of low confidence situations as i ey are reatly needed for risk-adverse decision making, especially considering that the IPCC scenarios fou central distribution rather than the highrisk tail and considering the presence of deep un ertainty. Hinkel et al., (2015) argue that the IPCC's global mean sea-level rise scenarios do not necessan " $v$ provide the right information for coastal decisionmaking and risk management.

In this context, decisions on investing in uncertainty regarding the future clim e ma in inancially incorrect to directly use the output of a single RCP scenario directly as an pu sor infrastructure design, unless that scenario is considered to

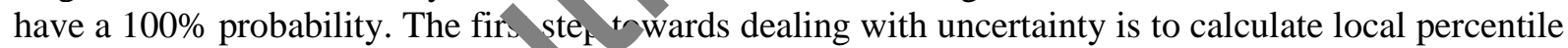
information (Kopp et al. 20\%). In ummary, to assess investments in LSLR adaptation it must be acknowledged that th will ome sources of uncertainty such as RCP probabilities, climate modeling, impact damas $\mathrm{w}$ ung, adaptation costs, socio-economic scenarios, etc. Accordingly, Hunt and Watkiss, (2010) pro de an overview of the state of the art in the quantification and valuation of climate risks at city scale. 'hey conclude that many of the decisions relating to future urban development require information on climate change risks to cities.

Uncertainty is addressed in the fifth and latest IPCC Assessment Report (AR5) (IPCC, 2014) with the communication of the degree of certainty in assessment findings. In the case of global sea level rise (GSLR) the qualifier assigned is "likely". The IPCC GSLR information is clearly insufficient because (i) it is global in nature; (ii) there is no GSLR that is only expected because of the failure to weigh up the four scenarios; and (iii) the term "likely" covers a range of $66-100 \%$, making it difficult to use in standard stochastic models to obtain risk measures.

There are relatively few applications that cover adaptation alternatives or investment projects. One of the few is Kontogianni et al. (2014), which explores modern management tools for assessing the economic impacts of SLR and the effectiveness of proactive coastal adaptation under uncertain conditions on the Greek coast. A second example is the paper by Woodward et al., (2011) on flood risk management in the Thames Estuary.

\footnotetext{
1 This measure is also known as $\mathrm{C}-\mathrm{VaR}$ or tail loss.
} 
Without adaptation, $0.2-4.6 \%$ of the world's population is expected to be flooded annually in 2100 under $25-123 \mathrm{~cm}$ of global mean sea-level rise and the associated annual costs could reach $0.3-9.3 \%$ of global GDP (Hinkel et al., 2014). The impacts of sea-level rise (SLR) in 83 developing countries are assessed by Dasgupta et al., (2009), whose results show a loss of global GDP ranging from 1.3\% to $6.05 \%$ for projected sea-level rises of $1 \mathrm{~m}$ and $5 \mathrm{~m}$ respectively. An assessment of the risks of coastal extremes for the coast of California (Heberger et al., 2011) estimates that 480,000 people, a wide range of critical infrastructures, vast areas of wetlands and other natural ecosystems, and nearly $\$ 100$ billion in property along the California coast are at increased risk from flooding from a 1.4-meter sea-level rise if no adaptation actions are taken.

Risk management is a fundamental policy response to climate change: Robust approaches that consider flexibility and the time dimension can be very valuable in supporting decision-making under uncertainty (Chambwera et al., 2014).

Abadie et al. (2016) calculate the risks for major European coastal cities under the RCP2.6, RCP4.5, and RCP 8.5 scenarios using local information. Their results show that in the worst cases, despite their low probability of occurrence, the scale of the damage is huge in comparison to annual average figures. More recently, Abadie et al. (2017) analyze expected damage and risk measures for 120 major coastal world cities under the same scenarios and the need for adaptation investments when the risk is greater than a given percentage of city-level GDP. In both studies their results depend on the fulfillment of the corresponding scenarios. Both papers use stochastic diffusion models.

Other studies have developed frameworks to account for the expect d lo ses fi sm sea-level rise and coastal extreme events using a different methodologies. For instance, oet e et al. (2013) use extreme value theory with the block-maxima approach for two Danish cit es: 0 pe. hagen and Kalundborg. They analyze expected damage and the standard deviation as a fu ctic of varying location and scale parameters of the generalized extreme value distribut on (GE'). Boettle et al. (2016) likewise use a Generalized Pareto Distribution (GPD) to assess the mpact of sea-level rise as well as potential protection measures against flood damage for the aforesala two cities. They assume that a rise in mean levels results in a shift of today's sea level distrib on without using future expected RCP information.

In this study I use a stochastic diffusion mod to ssus the expected damage and risk measures for 120 major world coastal cities due to climate an soci -economic effects under uncertainty. The model is based on regionalized IPCC RCP su n r10 for cach city. I use stochastic SLR values rather than the fixed values used in many studies 2 , s enavles risk measures to be calculated. The paper essentially makes three contributions: (i) As a ove y I propose a methodology based on a stochastic diffusion model together with Monte Can simulation for building a global stochastic scenario to assign probabilities on three RCPs (2. 4.5 md 8.5). This methodology enables the adaptation decision-making process based on the $\mathrm{p}$ bay ity assigned to the IPCC scenarios ; (ii) I apply that methodology to 120 coastal cities for certain mbinations of the RCPs scenario probabilities and obtain expected damage and risk measurements us $g$ Expected Shortfall(ES) along with their changes over time from the present to the year 2100; and (iii) I analyze expected damage and risks for World Bank income groups. The paper highlights the high economics risk that will be faced in the future by some mega-cities in China and the United States (USA).

The paper is organized as follows: Section 2 is dedicated to Material and Methods, and describes the stochastic diffusion model, its calibration, the Monte Carlo simulation process, the risk measure, and the damage function. Section 3 describes the calculation of the combined scenario for assigning probabilities to the three RCP scenarios. Section 4 presents the results at the following levels: (i) city; (ii) continent; (iii) Word Bank income group; and (iv) some relevant countries (USA and China). Section 5 contains a discussion and section 6 concludes. 


\section{Material and Methods}

\subsection{A stochastic approach to modeling global sea-level rise}

The IPCC report (2013) provides a range of estimates of global sea level rise (GSLR) for every decade from 2007 until the end of the century, according to different representative concentration pathways (RCPs). However this information is insufficient to analyze the risk in coastal cities because local SLR can differ significantly from global levels. Working with regionalized data is therefore critical for making decisions on adaptation investments.

Regionalized means and percentiles are calculated by Kopp et al., (2014) for three representative concentration paths. They do not consider RCP 6.0 in their projections because the figures for this pathway are nearly identical to those for RCP 4.5. The calculations of Koop et al. (2014) take into account changes in ocean dynamics, static equilibrium effects, glacial isostatic adjustments, and other local non-climatic drivers such as groundwater depletion, sediment compaction, and tectonic processes.

Using the data on medians and percentiles from Kopp et al. (2014), a continuous stochastic Geometric Brownian Motion $(\mathrm{GBM})^{2}$ model was calibrated to obtain the probability distr bution of relative SLR at each moment in time for each coastal city analyzed in each scenario (to t ree of the latest IPCC emission scenarios or Representative Concentration Pathways: RCPs _.0, 5 an 8.5). This means 120 coastal cities and three scenarios for each city, entailing $360 \mathrm{GBM}$. odel witir different parameters. The stochastic diffusion models derived and the correspond ig a ce anties formed the basis for assessing different actions, as shown below. These GBMod 's ha e enabled an LSLR distribution function to be drawn up that is log-normal at all tim is. The expected LSLR drift was obtained by minimizing the sum of the square of the differences wit the the retical median values (2030, 2050 and 2100). The volatility was calculated with the $95^{\text {th }}$ percentrom 2100 using log-normal distribution properties.

The detailed parameter calculation process $j$ in Appendix. Figure 1 shows a diagram of the calculation process. The stored values are us $d$ to $b$ iild mixed scenarios resulting from the probabilistic combination of the three basic scenzrio

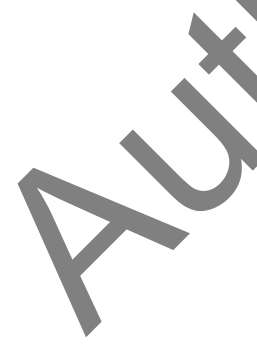

\footnotetext{
2 The Geometric Brownian Motion (GBM) diffusion model is a very common model defined as "a stochastic process often assumed for asset prices where the logarithm of the underlying variable follows a generalized Wiener process" (Hull, 2012). Note that in a GBM stochastic process the median is not equal to the mean.
} 


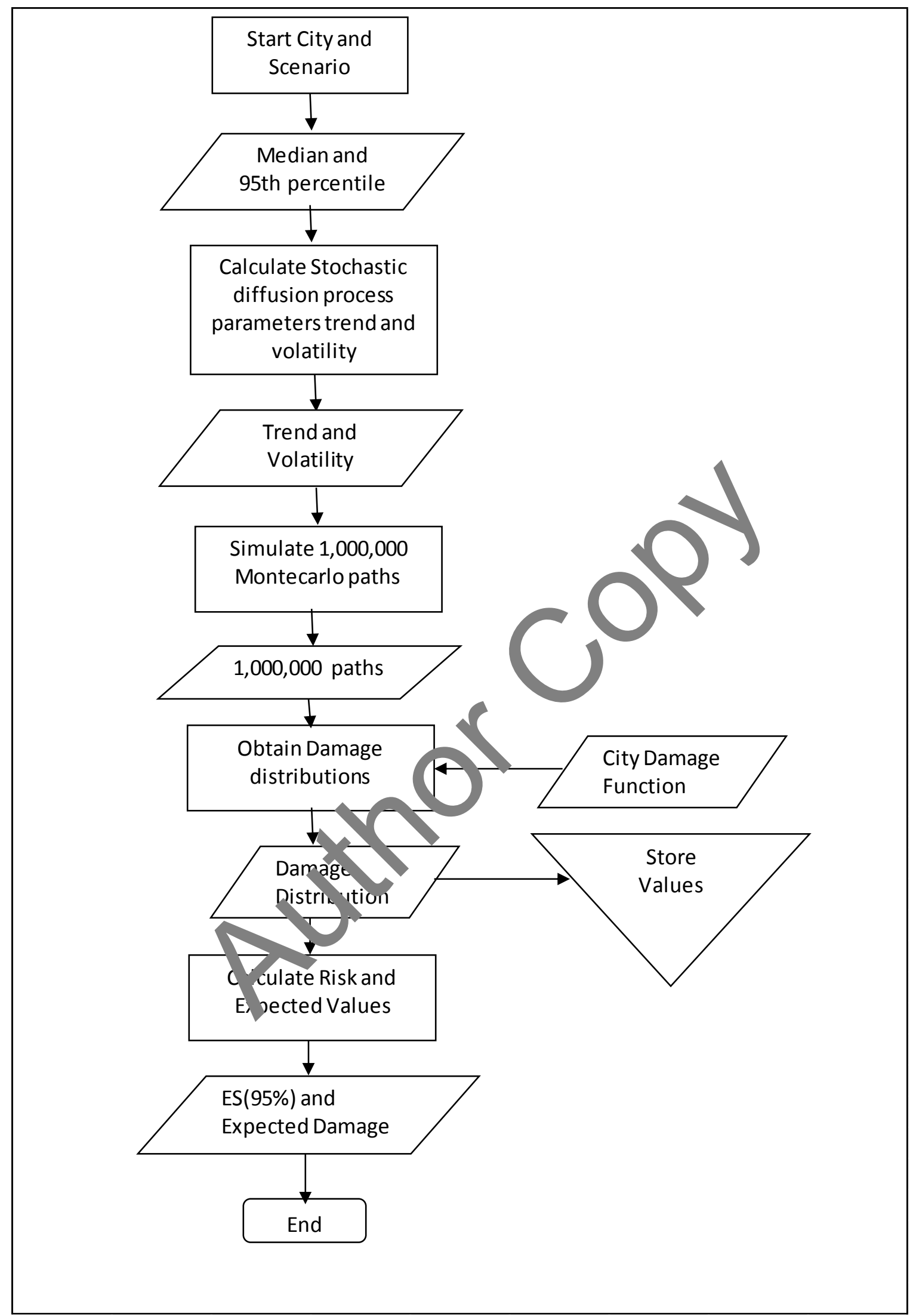

Figure 1. Diagram of the calculation process 


\subsection{Monte Carlo Simulation}

In this study I used 1,000,000 Monte Carlo simulations for each case, i.e. the combination of the climateinduced SLR scenario (RCP2.6, RCP4.5, RCP8.5) and time (2020 - 2100 with five year intervals), which was linked to socio-economic development and to each city. The number of simulations enabled me to approximate almost exactly the theoretical distribution of SLR for each city at time $t$. The detailed Monte Carlo simulation process is shown in the supplementary material.

Table 1 shows the SLR mean, median and $95^{\text {th }}$ percentile for 2011 for the three RCP scenarios in selected cities. RCP 2.6 provides the most optimistic SLR for any time, while RCP 8.5 presents the most pessimistic values. The figures for RCP 4.5 are very close to each other, showing a middle-of-the-road path (Abadie et al., 2017).

The Table 1 median and percentille $95^{\text {th }}$ figures are almost exactly the same as those calculated by Kopp et al. (2014). However, note that I now have a stochastic diffusion process that generates a log-normal distribution for any time $t$.

Table 1 shows that in 2100 the most risky scenario (RCP 8,5) for some cities expects a mean SLR of more than one meter, with the case of Bangkok standing out with an expect $\wedge$ d SLR of more than two meters. The $95^{\text {th }}$ percentile shows that in the $5 \%$ of worse cases the SLR could ise more than one and a half meters in some cities, such as Guangzhou, New Orleans, Bangkok, Calcum Osaka, Shanghai, New York, Zhanjiang, Surat, Hirosima, Houston, and Virginia Beach.

Table 1: Median, Mean and 95\% Percentile Simulated Values for 200 (ce time ers).

\begin{tabular}{|c|c|c|c|c|c|c|c|c|c|c|}
\hline \multirow{2}{*}{ no. } & \multirow{2}{*}{ City } & \multicolumn{3}{|c|}{$\mathrm{RCP} 2.6$} & \multicolumn{3}{|c|}{$\mathrm{RCP} 4.5$} & \multicolumn{3}{|c|}{ RCP 8.5} \\
\hline & & Median & Mean & $\mathrm{P}$ ) & edian & Mean & P95 & Median & Mean & P95 \\
\hline 1 & GUANGZHOU GUANGDONG & 51.6 & & 111.9 & 61.3 & 65.4 & 111.9 & 83.0 & 87.1 & 150.0 \\
\hline 2 & NEW ORLEANS & 121.6 & & 160.7 & 131.5 & 132.1 & 160.7 & 149.0 & 149.9 & 199.0 \\
\hline 3 & MUMBAI & $T$ & & 81.7 & 55.4 & 57.6 & 81.7 & 76.0 & 78.7 & 124.0 \\
\hline 4 & KRUNG THEP (BANGKOK) & & & 206.8 & 180.7 & 181.1 & 206.8 & 202.0 & 202.6 & 249.0 \\
\hline 5 & KOLKATA (CALCUTTA) & & 01.6 & 137.8 & 111.3 & 112.3 & 137.8 & 129.0 & 130.3 & 176.0 \\
\hline 6 & OSAKA & & 91.6 & 131.7 & 100.4 & 101.6 & 131.7 & 124.0 & 125.5 & 177.0 \\
\hline 7 & ALEXANDRIA & & 49.8 & 107.6 & 56.3 & 58.0 & 107.6 & 74.0 & 76.4 & 123.0 \\
\hline 8 & GUAYAQUIL & 40.2 & 42.7 & 78.3 & 49.2 & 51.7 & 78.3 & 69.0 & 71.8 & 117.0 \\
\hline 9 & SHENZEN & 39.4 & 42.6 & 82.7 & 50.4 & 53.3 & 82.7 & 71.0 & 74.3 & 123.0 \\
\hline 10 & SHANGHAI & 75.6 & 77.3 & 119.7 & 87.4 & 89.3 & 119.7 & 109.0 & 111.3 & 165.0 \\
\hline 11 & TIANJIN & 49.5 & 52.5 & 101.7 & 62.3 & 64.9 & 101.7 & 84.0 & 86.9 & 142.0 \\
\hline 12 & TOKYO & 46.3 & 48.7 & 88.5 & 57.3 & 59.6 & 88.5 & 81.0 & 83.9 & 136.0 \\
\hline 13 & HAI PHONG & 51.3 & 53.4 & 91.5 & 61.3 & 63.3 & 91.5 & 81.0 & 83.4 & 131.0 \\
\hline 14 & NAGOYA & 11.2 & 16.5 & 53.5 & 21.2 & 26.2 & 53.5 & 45.0 & 50.3 & 102.0 \\
\hline 15 & THÀNH-PHO-HO-CHÍ-MINH & 61.6 & 63.9 & 107.8 & 72.3 & 74.5 & 107.8 & 92.0 & 94.5 & 146.0 \\
\hline 16 & ABIDJAN & 29.4 & 32.0 & 66.6 & 39.1 & 41.7 & 66.6 & 60.0 & 62.9 & 108.0 \\
\hline 17 & VISAKHAPATNAM & 39.4 & 41.8 & 77.6 & 49.2 & 51.5 & 77.6 & 67.0 & 69.9 & 116.0 \\
\hline 18 & BOSTON & 57.7 & 60.1 & 103.1 & 70.4 & 72.7 & 103.1 & 91.0 & 93.9 & 149.0 \\
\hline 19 & NEW YORK & 62.9 & 65.1 & 107.3 & 75.6 & 77.8 & 107.3 & 96.0 & 98.8 & 154.0 \\
\hline 20 & ZHANJIANG & 65.3 & 67.3 & 111.4 & 75.2 & 77.3 & 111.4 & 96.0 & 98.4 & 151.0 \\
\hline 21 & SURAT & 77.5 & 79.3 & 121.7 & 88.4 & 90.1 & 121.7 & 109.0 & 111.0 & 161.0 \\
\hline 22 & MIAMI & 54.3 & 55.9 & 93.4 & 64.3 & 65.8 & 93.4 & 84.0 & 85.9 & 132.0 \\
\hline 23 & GRANDE VITORIA & 50.4 & 52.4 & 90.6 & 60.2 & 62.2 & 90.6 & 80.0 & 82.5 & 132.0 \\
\hline 24 & KHULNA & 65.5 & 67.7 & 110.7 & 76.4 & 78.6 & 110.7 & 94.0 & 96.5 & 148.0 \\
\hline
\end{tabular}




\begin{tabular}{|c|c|c|c|c|c|c|c|c|c|c|}
\hline 25 & XIAMEN & 51.4 & 53.7 & 92.6 & 61.2 & 63.5 & 92.6 & 83.0 & 85.8 & 137.0 \\
\hline 26 & FUKUOKA-KITAKYUSHU & 47.4 & 49.9 & 88.6 & 57.4 & 60.0 & 88.6 & 81.0 & 84.1 & 135.0 \\
\hline 27 & CHENNAI & 41.3 & 43.9 & 79.6 & 51.4 & 54.0 & 79.6 & 71.0 & 73.9 & 119.0 \\
\hline 28 & LOMÉ & 61.6 & 63.1 & 99.8 & 71.4 & 72.9 & 99.8 & 91.0 & 93.0 & 140.0 \\
\hline 29 & VANCOUVER & 26.1 & 29.4 & 64.1 & 33.0 & 35.9 & 64.1 & 46.0 & 49.0 & 88.0 \\
\hline 30 & HIROSHIMA & 75.6 & 77.1 & 116.7 & 85.5 & 87.2 & 116.7 & 109.0 & 111.1 & 163.0 \\
\hline 31 & HOUSTON & 95.7 & 96.7 & 135.8 & 105.4 & 106.3 & 135.8 & 123.0 & 124.4 & 173.0 \\
\hline 32 & SAN FRANCISCO & 50.4 & 52.3 & 88.6 & 58.2 & 60.2 & 88.6 & 75.0 & 77.2 & 122.0 \\
\hline 33 & TAIPEI & 49.4 & 51.9 & 93.7 & 59.2 & 61.8 & 93.7 & 82.0 & 85.1 & 139.0 \\
\hline 34 & KOCHI (COCHIN) & 52.4 & 54.7 & 91.7 & 62.3 & 64.7 & 91.7 & 84.0 & 86.7 & 134.0 \\
\hline 35 & TAMPA-ST. PETERSBURG & 59.6 & 61.3 & 98.8 & 68.4 & 70.0 & 98.8 & 88.0 & 90.2 & 138.0 \\
\hline 36 & SAN JUAN & 51.6 & 53.6 & 89.9 & 59.3 & 61.3 & 89.9 & 78.0 & 80.4 & 126.0 \\
\hline 37 & HONG KONG & 41.3 & 44.0 & 83.5 & 51.1 & 53.8 & 83.5 & 72.0 & 75.0 & 124.0 \\
\hline 38 & WASHINGTON DC & 62.7 & 64.1 & 104.9 & 74.3 & 75.7 & 104.9 & 93.0 & 94.9 & 146.0 \\
\hline 39 & NINGBO & 53.3 & 55.5 & 96.5 & 64.2 & 66 & 96.5 & 86.0 & 88.7 & 141.0 \\
\hline 40 & VIRGINIA BEACH & 71.6 & 73.2 & 114.8 & 83.6 & (5) & 114.8 & 102.0 & 104.0 & 156.0 \\
\hline
\end{tabular}

\subsection{Risk Measuring}

The central distribution measures (mean and median) or w. SLR projections do not provide all the information that needs to be considered from a bastal risk management perspective: information is required on the "upper-tail end" of the probal-1 ity 'istribution, i.e. the worst-case scenario (Hinkel et al., 2015). Risk measures are very useful ana ytica ools in situations of uncertainty and have often been used in economics to account for uncert tie of rices or other other variables in investment projects (Abadie and Chamorro, 2013). In this aper ve use Expected Shortfall (ES) as a coherent ${ }^{3}$ measure of risk (Artzner et al., 1999). ES is a g. d r r ' measure and in particular makes it possible to perform many large-scale calculations and sho tha yumerical efficiency and stability (Rockafellar and Uryasev, 2002).

Expected Shortfall (ES Is he mun expected loss in the (1- $\alpha) \%$ worse cases, so ES (95\%) is the mean expected loss in the wor $t \%$ or cases. The GBM distribution model enables the risk corresponding to any value of $\alpha$ to be esti ated, but in this study I focus only on the worst $5 \%$ of cases, so $1-\alpha=95 \%$, although the model can be calculated with other values.

With a stochastic model it is possible to generate a large number of scenarios using Monte Carlo simulation methods and to calculate ES(1- $\alpha)$ fairly accurately. That is the numerial method approach followed in this paper.

\subsection{The Damage Function}

A recent study by Hallegatte et al. (2013) estimates the cost of annual average damage due to the combined effect of sea-level rise and extreme events in 136 major mega-cities. The authors define a damage function in which flood losses depend on the following variables: global sea-level rise $(S)$, the level of protection in place in coastal cities $(P)$, subsidence $(S U B)^{4}$, extreme events $(E)$, the socioeconomic scenario $(S E)$, the defense failure model, and the characteristics of defenses $(D F)$.

\footnotetext{
${ }^{3}$ It is considered that a coherent risk measure R(D), in which D represents damage, must meet the following four conditions: monotonicity, sub-additivity, positive homogeneity and translation invariance.

${ }^{4}$ Defined as the sum of subsidence and land-uplift.
} 


$$
D=f(S, P, S U B, E, S E, D F)
$$

The cost function provided in their paper, which relates damage to SLR, served as an input for the study presented in this paper. However Hallegatte et al. (2013) follow a deterministic approach to SLR, while I model it in a stochastic way to account for uncertainty at local level. The modeling is done following the latest IPCC scenarios RCP2.6, RCP4.5 and RCP8.5 regionalized by Kopp et al. (2014). In addition, I use the risk measure defined above to develop a risk-based assessment of potential damage. Only 120 of the cities analyzed by Hallegatte et al., (2013) are considered in the study by Kopp et al., (2014), so I limit my study to the 120 mega-cities that appear in both papers.

The damage function is based on two main components: The first is local sea-level rise at each city, which is estimated using the stochastic GBM model as described in Section 2.1. The three LSLR scenarios are distinguished via the index $i$, so that at a time $t$ the local SLR in scenario RCP2.6 and city $\mathrm{k}$ is $S_{t}^{i, k}$, assuming the stochastic behavior defined as laid out. The subsidence in each city is not considered in my damage function as it is taken into account together with other local determinants in the SLR regionalization process developed by Kopp et al. (2014).

The second component of the damage function is represented by the socio-economic development of each city in the future, as defined by Hallegatte et al. (2013)5. Accordingly, tamage also varies with time $t$ in a deterministic way, due to the effect of the socio-economic scorric Note that the function does not include extreme events as a variable. However, the original vo from Iallegatte et al. (2013) used in this paper incorporate the probability of extreme events obta ned $1 \mathrm{om}$ te DIVA model. This DIVA model information is also used because it enables homoge ro c a rparisons to be made between cities. The model proposed could be used in a city with me ( mag inturmation if such information is obtained in the future.

In areas where there are coastal defenses I assume that ey fail o provide any protection once they are overcome by flooding. This means that the damage function or each local SLR scenario $i$ and for each city $k$ at each time $T$ is defined as follows:

At time $t$ the function has the follow ng $\mathrm{rm}$ :

$$
D_{t}^{i, k}=f\left(S_{t}^{i, k}, t\right)
$$

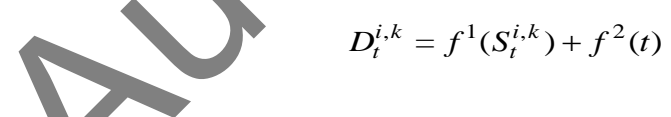

where $f^{1}\left(S_{t}^{i, k}\right)$ represen s the impact of sea-level rise in city $k$ at time $\mathrm{t}$ in scenario $i$, including subsidence, while $f^{2}(t)$ shows the socio-economic impacts in the absence of SLR.

In this way, following the data from Hallegatte et al. (2013), I calibrate a continuous damage function for each city using discontinuous data. The main factor that increases damage is found to be $f^{1}\left(S_{t}^{i, k}\right)$, followed by socio-economic development over the years. Obviously, both factors contribute to increasing the risk over time.

\footnotetext{
${ }^{5}$ Hallegatte et al. (2013) develop three possible socio-economic scenarios: a constant scenario, a scenario with no city limit (every city within a country grows at the same rate), and a scenario with city limits assuming that no city will exceed 35 million inhabitants. In this study I use the data for this last scenario.
} 


\section{Calculations}

\subsection{Building a combination of IPCC SLR scenarios}

Now, if probabilities $p_{i}$ are assigned to the three IPCC scenerios used here with $p_{1}+p_{2}+p_{3}=1$ , the expected sea level rise for city $k$ emerges, as shown in equation (4)

$$
E_{0}\left(S_{t}^{k}\right)=V_{0}^{k}\left(p_{1} e^{\alpha^{1, k} t}+p_{2} e^{\alpha^{2, k} t}+p_{2} e^{\alpha^{2, k} t}\right)-\left(p_{1} B_{0}^{1, k}+p_{2} B_{0}^{2, k}+p_{2} B_{0}^{3, k}\right)
$$

The total variance $\operatorname{Var}\left(S_{t}^{k}\right)=\operatorname{Var}\left(V_{t}^{k}\right)$ for city $\mathrm{k}$ is shown in Equation (5).

$$
\sum_{i=1}^{3} p_{i}\left[\operatorname{Var}\left(V_{t}^{i, k}\right)+\left(E_{0}\left(S_{t}^{i, k}\right)\right)^{2}\right]-\left(E_{0}\left(S_{t}^{k}\right)\right)^{2}
$$

An infinite number of scenario combinations are possible. The methodology proposed enables any combination to be calculated. However I calculate three additional scenarios:

A) An equal probability scenario where RCP6.0 is represented by the RCP4.5 scenario values $\left(\mathrm{p}_{1}=25.00 \%, \mathrm{p}_{2}=50.00 \%\right.$ and $\left.\mathrm{p}_{3}=25.00 \%\right)$.

B) An equal probability scenario discarding the possibility of the $\mathrm{DCH} .6$ scenario $\left(\mathrm{p}_{1}=0.00 \%\right.$, $\mathrm{p}_{2}=66.67 \%$ and $\mathrm{p}_{3}=33.33 \%$ ).

C) A scenario with equal probability for RCP4.5 and $\left.\mathrm{RC} 8.5, \mathrm{p}_{1}=0\right) 0 \%, \mathrm{p}_{2}=50.00 \%$ and $\left.\mathrm{p}_{3}=50.00 \%\right)$.

The results for the case of New Orleans are shown in Table , where the meoretical values are compared with the Monte Carlo simulated values for the original IPCC scenarios nd equa probability scenario A) in the year 2100 .

Table 2: New Orleans Mean and Variance Scenario 25\% \{CP2.6, 50\% RCP4.5, 25\% RCP8.5 in 2100 (SLR in centimeters).

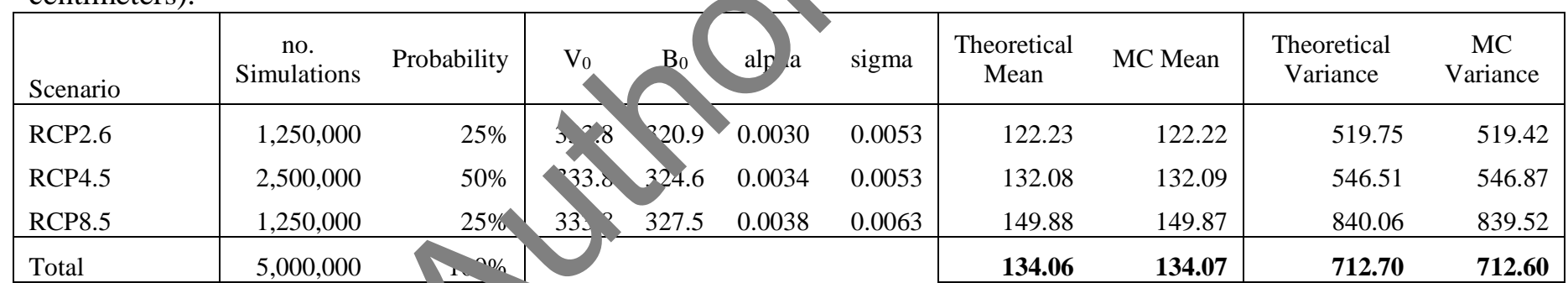

Table 2 shows that the Tonte Carlo method, using 5,000,000 simulations in this case, is a good procedure for obtaining an SLR distribution because the mean and variance values are almost identical to the theoretical ones.

Observe that in the combined scenario the mean is the weighted figure for three RCP means, while the variance is higher than the weighted values, which is due to the influence of the more volatile scenarios in the risk, which is greater than the probability for this scenario.

\subsection{Obtaining the mean and risk of damage with a combination of IPCC SLR scenarios}

After obtaining the 1,000,000 Monte Carlo simulations of SLR for each city and each scenario I selected a path depending on the probabilities. For example, in the case of equal probability scenario A) I took path 250,000 from RCP2.6, path 500,000 from RCP4.5 and path 250,000 from RCP8.5. Now with this total of 1,000,000 paths I used the damage function to obtain the corresponding damage distribution. With this distribution I calculated the mean value and the ES(95\%), in the latter case with the mean of 
the 50,000 worst values. Figure 2 shows the ES(95\%) in the case of New Orleans as a function of the probability of the IPCC scenarios.

Of the three additional scenarios it is the most pessimistic ones which have most influence on the value of $\operatorname{ES}(95 \%)$.

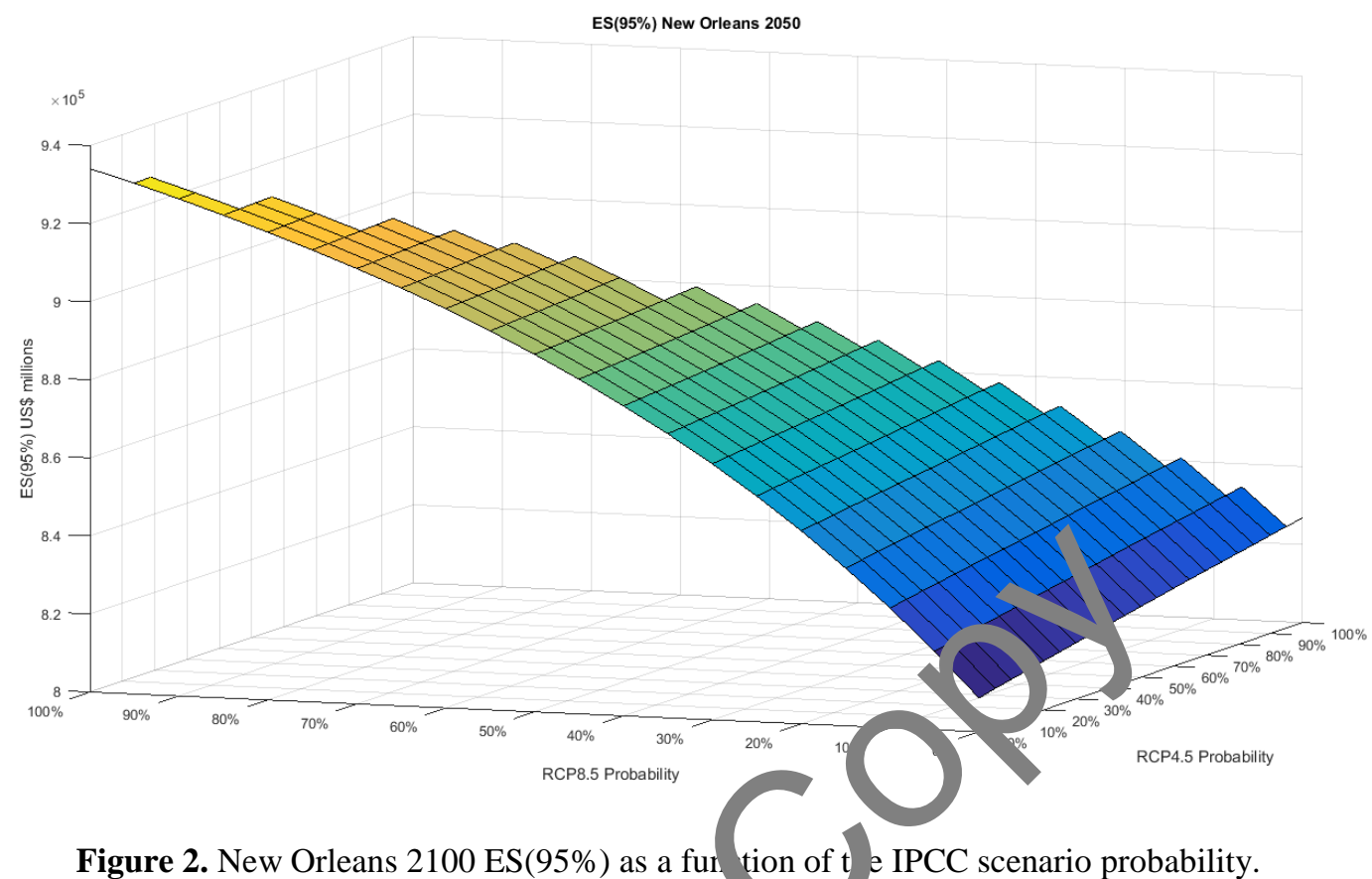

Figure 2 also shows the greater impact on risk $m$ asuring of the probability of the RCP 8.5 scenario. Some probability combinations are not possible bo ause they must add up to one.

\section{Results}

\subsection{Results for weighted scena ios}

Table 3 shows the ex acted a ma ge in the 15 most strongly affected cities in 2100 in the equal probability scenario (2. \% $2.6,50 \%$ RCP 4.5 and 25\% RCP 8.5). The table includes many Asian cities, but New Orleans the city with the greatest expected damage. It can be seen that the expected damage grows rapidly $w$ th time, so if mitigation measures are insufficient there will need to be substantial investment in adaptation in many coastal cities. New Orleans, Guangzhou, Bangkok, Mumbai and Calcutta are the five cities with the greatest expected damage in 2100. In the case of New Orleans the expected damage in that year is US\$1,251,732 millions.

This mean measurement is important but insufficient, because it does not show the extreme effects of low-probability but high damage. The $\mathrm{ES}(95 \%)$ risk measure is presented in Table 4, and shows that the risk is greater in Guangzhou than in New Orleans. This is because the variance in samage is greater in Guangzhou, i.e. there is greater uncertainty there. This differentiated behavior can be seen in Figure 3.

Table 3: Ranking of cities considering expected damage in 2025-2100 under the 25\% RCP2.6, 50\% RCP4.5 and $25 \%$ RCP8.5 scenario (millions of US\$)

\begin{tabular}{|r|l|l|llll|}
\hline no. & \multicolumn{1}{|c|}{ CITY } & \multicolumn{1}{|c|}{ Continent } & 2025 & 2050 & 2075 & 2100 \\
\hline 1 & NEW ORLEANS & North America & 259,129 & 563,210 & 892,664 & $1,251,732$ \\
2 & GUANGZHOU GUANGDONG & Asia & 136,512 & 388,171 & 743,593 & $1,196,517$
\end{tabular}




\begin{tabular}{|r|l|l|rrrr|}
3 & KRUNG THEP (BANGKOK) & Asia & 124,674 & 339,300 & 575,793 & 835,836 \\
4 & MUMBAI & Asia & 24,707 & 143,895 & 337,767 & 594,853 \\
5 & KOLKATA (CALCUTTA) & Asia & 74,326 & 214,021 & 377,679 & 567,378 \\
6 & OSAKA & Asia & 83,276 & 192,192 & 309,534 & 442,660 \\
7 & ALEXANDRIA & Africa & 12,482 & 71,246 & 170,358 & 296,610 \\
8 & SHANGHAI & Asia & 10,186 & 74,122 & 163,979 & 272,600 \\
9 & GUAYAQUIL & South America & 7,668 & 45,824 & 138,752 & 271,363 \\
10 & SHENZEN & Asia & 4,215 & 33,965 & 108,926 & 219,958 \\
11 & TIANJIN & Asia & 19,304 & 65,712 & 127,227 & 201,709 \\
12 & TOKYO & Asia & 16,013 & 70,683 & 130,379 & 200,311 \\
13 & HAI PHONG & Asia & 4,327 & 29,442 & 83,092 & 152,770 \\
14 & THÀNH-PHO-HO-CHÍ-MINH & Asia & 28,732 & 69,156 & 118,874 \\
15 & NEW YORK & North America & 7,643 & 30,262 & 61,809 & 100,239 \\
\hline
\end{tabular}

Table 4: Ranking of cities considering the $2100 \mathrm{ES}(95 \%)$ under the $25 \% \mathrm{RCP} 2.6,50 \%$ RCP4.5 and $25 \%$ RCP8.5 scenario (millions of US\$).

\begin{tabular}{|c|c|c|c|c|c|c|}
\hline no. & CITY & Continent & 2025 & 050 & 2075 & 2100 \\
\hline 1 & GUANGZHOU GUANGDONG & Asia & & 24 & $1,780,975$ & $2,800,756$ \\
\hline 2 & NEW ORLEANS & North America & & $8 6 3 \longdiv { 5 7 }$ & $1,326,645$ & $1,832,466$ \\
\hline 3 & MUMBAI & Asia & & 384,399 & 774,892 & $1,310,529$ \\
\hline 4 & KRUNG THEP (BANGKOK) & Asia & & 486,422 & 793,745 & $1,133,409$ \\
\hline 5 & KOLKATA (CALCUTTA) & Asia & & 355,130 & 596,635 & 881,334 \\
\hline 6 & OSAKA & Asia & 158,224 & 321,041 & 507,388 & 723,781 \\
\hline 7 & ALEXANDRIA & Afric & 65,633 & 235,066 & 443,006 & 705,048 \\
\hline 8 & GUAYAQUIL & Sout America & 25,554 & 162,699 & 371,707 & 661,637 \\
\hline 9 & SHENZEN & & 16,046 & 138,429 & 320,346 & 577,702 \\
\hline 10 & SHANGHAI & & 52,401 & 181,598 & 338,425 & 532,281 \\
\hline 11 & TIANJIN & & 65,756 & 167,634 & 292,293 & 447,426 \\
\hline 12 & TOKYO & Asia & 71,616 & 161,165 & 275,361 & 423,355 \\
\hline 13 & HAI PHONG & Asia & 16,568 & 103,580 & 212,364 & 350,530 \\
\hline 14 & NAGOYA & Asia & 9,588 & 74,543 & 146,773 & 268,807 \\
\hline 15 & THÀNH-PHO-HC & Asia & 20,351 & 79,188 & 152,876 & 244,446 \\
\hline
\end{tabular}




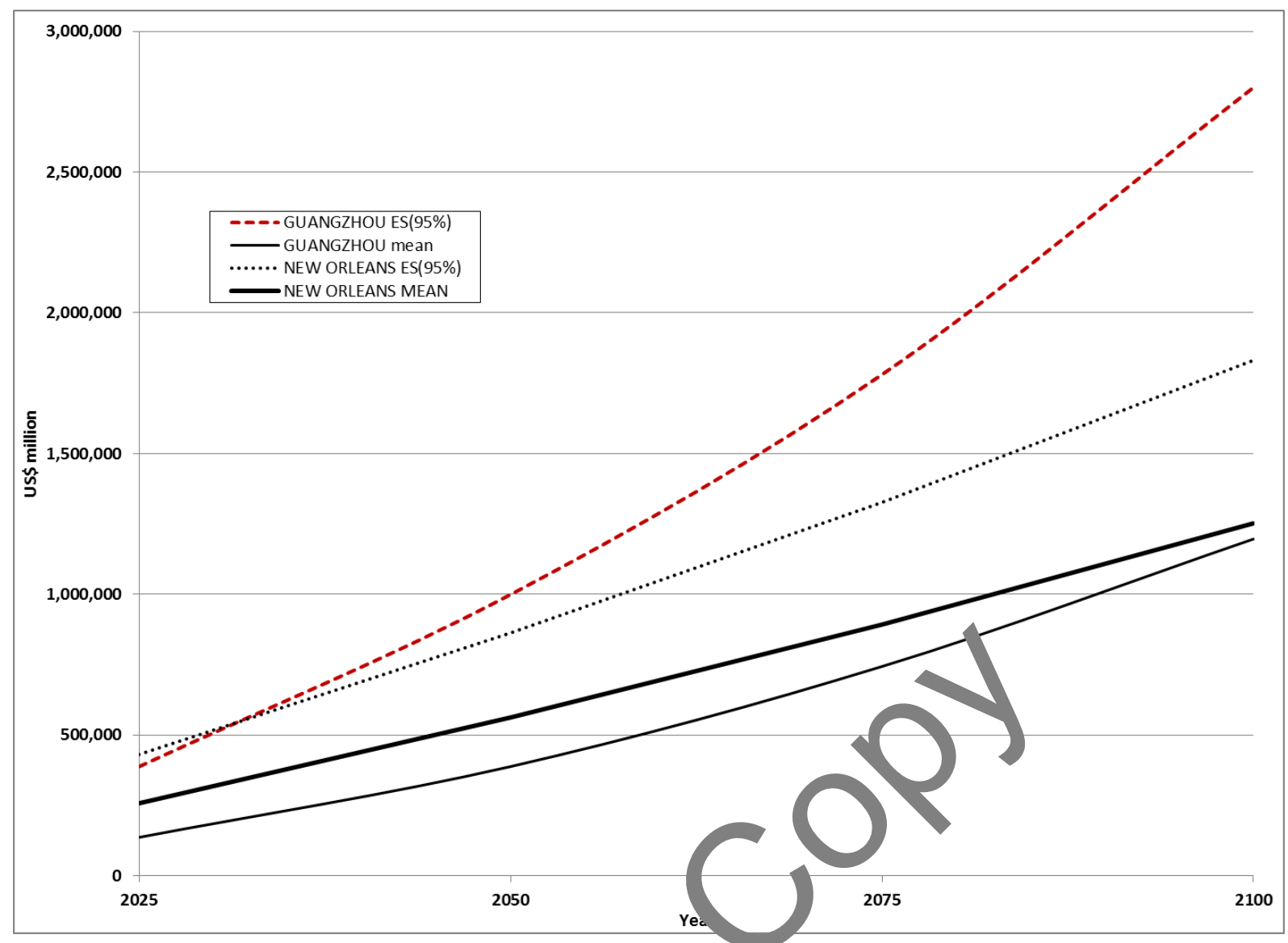

Figure 3. Differentiated behavior between New Or cans and Guangzhou in 2100 in the equal probability scenario.

Table 4 shows that in the case of Guangzhou in 210 the ES(95\%) is US\$2,800,756 millions, i.e. in the $5 \%$ of worse cases that is the amount of the 5\% of worse cases in 2100 will ex ed $\$ \$ 500,000$ millions in ten cities, eight of them in Asia.

Table 5 shows the five cities at most isk each continent under the three IPCC and the three combined scenarios. In general the scenario can classified from lowest to highest risk as RCP 2.6, RCP 4.5, A), B), C), RCP 8.5. This is the in Alexandria, where the $95 \%$ percentile gives a higher figure in RCP2.6 than RCP4. ung th ata in Kopp et al. (2014). Asian and North American cities are at most risk while Europea $c$ ies are at least risk. The African cities stand at an intermediate level of risk and the risk level in the $\mathrm{m}$ ga-cities of Oceania is low. Table 5 also shows that in calculating risk levels the probability assigned to he riskiest scenario has a significant impact.

Table 5: Cities ranked by high $2100 \mathrm{ES}(95 \%)$ on each continent and for some scenarios (millions of US\$).

\begin{tabular}{|c|c|c|c|c|c|c|c|}
\hline RCP 2.6 & \multirow{3}{*}{ Continent } & $100.00 \%$ & $0.00 \%$ & $0.00 \%$ & $25.00 \%$ & $0.00 \%$ & $0.00 \%$ \\
\hline $\mathrm{RCP} 4.5$ & & $0.00 \%$ & $100.00 \%$ & $0.00 \%$ & $50.00 \%$ & $66.67 \%$ & $50.00 \%$ \\
\hline RCP 8.5 & & $0.00 \%$ & $0.00 \%$ & $100.00 \%$ & $25.00 \%$ & $33.33 \%$ & $50.00 \%$ \\
\hline GUANGZHOU & \multirow{5}{*}{ Asia } & $2,429,580$ & $2,627,065$ & $3,175,214$ & $2,800,756$ & $2,879,034$ & $2,970,759$ \\
\hline MUMBAI & & 998,779 & $1,154,451$ & $1,536,325$ & $1,310,529$ & $1,359,216$ & $1,419,409$ \\
\hline KRUNG THEP (BANGKOK) & & 996,605 & $1,058,297$ & $1,220,816$ & $1,133,409$ & $1,152,718$ & $1,177,355$ \\
\hline KOLKATA (CALCUTTA) & & 750,658 & 821,505 & 971,920 & 881,334 & 901,406 & 925,577 \\
\hline OSAKA & & 603,567 & 655,707 & 808,968 & 723,781 & 742,248 & 765,869 \\
\hline ISTANBUL & \multirow{3}{*}{ Europe } & 29,675 & 29,945 & 33,649 & 30,925 & 31,290 & 31,914 \\
\hline GLASGOW & & 2,775 & 3,264 & 4,424 & 3,667 & 3,829 & 4,021 \\
\hline LISBON & & 2,691 & 2,963 & 3,834 & 3,293 & 3,404 & 3,546 \\
\hline
\end{tabular}




\begin{tabular}{|c|c|c|c|c|c|c|c|}
\hline LONDON & & 941 & 1,040 & 1,493 & 1,245 & 1,296 & 1,366 \\
\hline HAMBURG & & 930 & 1,072 & 1,438 & 1,233 & 1,277 & 1,334 \\
\hline NEW ORLEANS & \multirow{5}{*}{ North America } & $1,607,000$ & $1,712,759$ & $2,002,232$ & $1,832,466$ & $1,869,115$ & $1,915,497$ \\
\hline BOSTON & & 172,121 & 197,229 & 256,750 & 219,865 & 227,817 & 237,474 \\
\hline NEW YORK & & 162,396 & 188,821 & 238,983 & 207,126 & 214,281 & 222,466 \\
\hline MIAMI & & 114,417 & 128,001 & 164,879 & 143,039 & 147,729 & 153,592 \\
\hline VANCOUVER & & 80,057 & 84,744 & 104,359 & 91,344 & 93,750 & 97,026 \\
\hline BRISBANE & \multirow{5}{*}{ Oceania } & 3,669 & 4,215 & 5,773 & 4,914 & 5,099 & 5,336 \\
\hline SYDNEY & & 3,312 & 3,878 & 5,316 & 4,521 & 4,693 & 4,910 \\
\hline PERTH & & 1,063 & 1,200 & 1,580 & 1,358 & 1,405 & 1,466 \\
\hline ADELAIDE & & 340 & 386 & 497 & 431 & 446 & 463 \\
\hline MELBOURNE & & 159 & 178 & 229 & 198 & 205 & 213 \\
\hline GUAYAQUIL & \multirow{5}{*}{ South America } & 511,478 & 585,778 & 780,811 & 661,637 & 687,194 & 718,394 \\
\hline GRANDE VITORIA & & 103,789 & 118,477 & 158,389 & 134,366 & 139,496 & 145,891 \\
\hline RIO DE JANEIRO & & 14,278 & 16,736 & 22,933 & 19,408 & 20,175 & 21,134 \\
\hline RECIFE & & 9,702 & 11,210 & 15,160 & 12,785 & 13,296 & 13,927 \\
\hline NATAL & & 4,724 & 5,454 & & 6,216 & 6,464 & 6,769 \\
\hline ALEXANDRIA & \multirow{5}{*}{ Africa } & 739,968 & 571,386 & y. & $7,5,048$ & 693,597 & 728,853 \\
\hline ABIDJAN & & 159,191 & 187,815 & & 219,933 & 229,823 & 242,200 \\
\hline LOMÉ & & 90,613 & $10,-, 045$ & 217 & 115,073 & 118,999 & 123,873 \\
\hline LAGOS & & 39,049 & 43,738 & 55,790 & 48,661 & 50,204 & 52,119 \\
\hline DAR-EL-SALAM & & 14,695 & $r_{8}$ & 22,201 & 18,971 & 19,667 & 20,519 \\
\hline
\end{tabular}

Tables 6, 7, and 8 show the trend over time in the $\mathrm{k}$ of damage for 25 mega-cities from 2050 to 2075 and 2100. These tables show high levels of isk $1 \mathrm{r}$ nore remote dates. The risk level rises over time. The top five cities most at risk are the same os a all times.

Table 6: Cities ranked by 2050 ES $5 \%$ damage in some scenarios (millions of US\$).

\begin{tabular}{|r|l|rrrrrr|}
\hline no. & RCP 2.6 & $\begin{array}{rrrrr}100.00 \% \\
\end{array}$ & $0.00 \%$ & $0.00 \%$ & $25.00 \%$ & $0.00 \%$ & $0.00 \%$ \\
\hline 1 & RCP 4.5 & $0.00 \%$ & $100.00 \%$ & $0.00 \%$ & $50.00 \%$ & $66.67 \%$ & $50.00 \%$ \\
2 & NUANGZHOU GUA. GDONG & $0.00 \%$ & $0.00 \%$ & $100.00 \%$ & $25.00 \%$ & $33.33 \%$ & $50.00 \%$ \\
3 & KRUNG THEP (BANGKOK) & 966,539 & 976,248 & $1,061,446$ & 999,324 & $1,008,713$ & $1,023,708$ \\
4 & MUMBAI & 449,846 & 467,128 & 523,386 & 486,422 & 494,117 & 503,760 \\
5 & KOLKATA (CALCUTTA) & 348,064 & 354,191 & 438,366 & 384,399 & 393,354 & 407,731 \\
6 & OSAKA & 325,955 & 341,546 & 386,322 & 355,130 & 361,646 & 369,404 \\
7 & ALEXANDRIA & 297,271 & 305,837 & 350,882 & 321,041 & 326,707 & 334,466 \\
8 & SHANGHAI & 283,555 & 192,951 & 241,864 & 235,066 & 214,094 & 222,625 \\
9 & GUAYAQUIL & 161,599 & 173,014 & 203,424 & 181,598 & 186,224 & 191,501 \\
10 & TIANJIN & 147,096 & 155,097 & 183,419 & 162,699 & 166,686 & 171,622 \\
11 & TOKYO & 162,009 & 162,128 & 180,091 & 167,634 & 169,205 & 172,346 \\
12 & SHENZEN & 146,901 & 152,672 & 179,323 & 161,165 & 164,568 & 169,169 \\
13 & HAI PHONG & 127,400 & 129,923 & 156,933 & 138,429 & 141,272 & 145,963 \\
14 & THÀNH-PHO-HO-CHÍ-MINH & 91,314 & 97,367 & 118,651 & 103,580 & 106,550 & 110,242 \\
15 & BOSTON & 73,192 & 75,794 & 87,645 & 79,188 & 80,730 & 82,792 \\
& & 67,840 & 71,179 & 85,337 & 75,457 & 77,310 & 79,768
\end{tabular}




\begin{tabular}{|l|l|llllll|}
16 & NEW YORK & 65,136 & 70,117 & 82,059 & 73,330 & 75,223 & 77,299 \\
17 & NAGOYA & 74,304 & 71,874 & 78,311 & 74,543 & 74,524 & 75,660 \\
18 & ZHANJIANG & 65,489 & 68,183 & 75,619 & 70,018 & 71,181 & 72,478 \\
19 & SURAT & 54,989 & 55,940 & 63,469 & 58,299 & 59,170 & 60,477 \\
20 & VISAKHAPATNAM & 45,433 & 48,497 & 62,440 & 52,712 & 54,505 & 56,923 \\
21 & ABIDJAN & 47,202 & 49,796 & 61,910 & 53,292 & 54,836 & 56,944 \\
22 & MIAMI & 47,567 & 49,724 & 58,333 & 52,231 & 53,389 & 54,887 \\
23 & FUKUOKA-KITAKYUSHU & 43,097 & 44,962 & 51,391 & 46,889 & 47,787 & 48,898 \\
24 & KHULNA & 42,673 & 44,738 & 50,942 & 46,362 & 47,290 & 48,371 \\
25 & XIAMEN & 40,266 & 42,542 & 49,182 & 44,344 & 45,339 & 46,494 \\
\hline
\end{tabular}

Table 7: Cities ranked by 2075 ES(95\%) damage in some scenarios (millions of US\$).

\begin{tabular}{|c|c|c|c|c|c|c|c|}
\hline no. & $\begin{array}{l}\text { RCP } 2.6 \\
\text { RCP } 4.5 \\
\text { RCP } 8.5 \\
\end{array}$ & $\begin{array}{c}100.00 \% \\
0.00 \% \\
0.00 \% \\
\end{array}$ & $\begin{array}{c}0.00 \% \\
100.00 \% \\
0.00 \% \\
\end{array}$ & $\begin{array}{c}0.00 \% \\
0.00 \% \\
100.00 \% \\
\end{array}$ & $\begin{array}{l}25.00 \% \\
50.00 \% \\
25.00 \% \\
\end{array}$ & $\begin{array}{c}0.00 \% \\
66.67 \% \\
33.33 \% \\
\end{array}$ & $\begin{array}{c}0.00 \% \\
50.00 \% \\
50.00 \% \\
\end{array}$ \\
\hline 1 & GUANGZHOU GUANGDONG & $1,624,758$ & $1,706,259$ & $1,967 \div 80$ & $1,780,975$ & $1,819,102$ & $1,862,802$ \\
\hline 2 & NEW ORLEANS & $1,196,100$ & $1,254,373$ & & $1,326,645$ & $1,351,607$ & $1,383,166$ \\
\hline 3 & MUMBAI & 637,604 & 700,903 & 897,19 & 774,892 & 800,514 & 832,281 \\
\hline 4 & KRUNG THEP (BANGKOK) & 712,839 & 750,47 & 85. 433 & 793,745 & 807,149 & 823,919 \\
\hline 5 & KOLKATA (CALCUTTA) & 525,039 & & 654,773 & 596,635 & 609,470 & 624,355 \\
\hline 6 & OSAKA & 443,021 & $470,7 \hat{1}$ & 563,126 & 507,388 & 519,176 & 534,081 \\
\hline 7 & ALEXANDRIA & 492,717 & 26471 & 485,079 & 443,006 & 425,256 & 445,065 \\
\hline 8 & GUAYAQUIL & $308,3,5$ & 341,431 & 431,328 & 371,707 & 384,487 & 399,301 \\
\hline 9 & SHANGHAI & & 315,030 & 383,807 & 338,425 & 348,548 & 359,909 \\
\hline 10 & SHENZEN & & 293,961 & 371,905 & 320,346 & 330,913 & 343,769 \\
\hline 11 & TIANJIN & & 275,425 & 327,324 & 292,293 & 299,212 & 307,870 \\
\hline 12 & TOKYO & 230,114 & 250,915 & 315,981 & 275,361 & 283,877 & 294,446 \\
\hline 13 & HAI PHONG & 175,297 & 194,922 & 245,824 & 212,364 & 219,609 & 228,003 \\
\hline 14 & THÀNH-PHO-F & 133,314 & 143,663 & 172,203 & 152,876 & 156,987 & 161,739 \\
\hline 15 & NAGOYA & 127,639 & 135,538 & 167,495 & 146,773 & 150,683 & 155,881 \\
\hline 16 & BOSTON & 115,965 & 128,152 & 160,611 & 139,266 & 143,809 & 149,186 \\
\hline 17 & NEW YORK & 110,105 & 123,941 & 151,368 & 132,780 & 137,008 & 141,565 \\
\hline 18 & ABIDJAN & 98,371 & 111,098 & 148,477 & 124,342 & 129,418 & 135,531 \\
\hline 19 & VISAKHAPATNAM & 100,135 & 112,735 & 147,489 & 124,504 & 129,375 & 135,122 \\
\hline 20 & ZHANJIANG & 105,277 & 113,378 & 133,111 & 119,595 & 122,572 & 125,861 \\
\hline 21 & SURAT & 91,883 & 97,732 & 115,147 & 103,732 & 106,141 & 109,021 \\
\hline 22 & MIAMI & 79,349 & 86,392 & 106,984 & 93,726 & 96,530 & 99,922 \\
\hline 23 & KHULNA & 75,633 & 82,409 & 97,048 & 86,763 & 89,076 & 91,528 \\
\hline 24 & GRANDE VITORIA & 67,853 & 75,274 & 96,607 & 82,732 & 85,668 & 89,192 \\
\hline 25 & XIAMEN & 68,033 & 74,953 & 92,997 & 81,206 & 83,761 & 86,731 \\
\hline
\end{tabular}

Table 8: Cities ranked by 2100 ES(95\%) damage in some scenarios (millions of US\$).

\begin{tabular}{|r|l|cccccc|}
\hline \multirow{2}{*}{ no. } & RCP 2.6 & $100.00 \%$ & $0.00 \%$ & $0.00 \%$ & $25.00 \%$ & $0.00 \%$ & $0.00 \%$ \\
& RCP 4.5 & $0.00 \%$ & $100.00 \%$ & $0.00 \%$ & $50.00 \%$ & $66.67 \%$ & $50.00 \%$ \\
& RCP 8.5 & $0.00 \%$ & $0.00 \%$ & $100.00 \%$ & $25.00 \%$ & $33.33 \%$ & $50.00 \%$ \\
\hline \multirow{2}{*}{1} & GUANGZHOU GUANGDONG & $2,429,580$ & $2,627,065$ & $3,175,214$ & $2,800,756$ & $2,879,034$ & $2,970,759$
\end{tabular}




\begin{tabular}{|c|c|c|c|c|c|c|c|}
\hline 2 & NEW ORLEANS & $1,607,000$ & $1,712,759$ & $2,002,232$ & $1,832,466$ & $1,869,115$ & $1,915,497$ \\
\hline 3 & MUMBAI & 998,779 & $1,154,451$ & $1,536,325$ & $1,310,529$ & $1,359,216$ & $1,419,409$ \\
\hline 4 & KRUNG THEP (BANGKOK) & 996,605 & $1,058,297$ & $1,220,816$ & $1,133,409$ & $1,152,718$ & $1,177,355$ \\
\hline 5 & KOLKATA (CALCUTTA) & 750,658 & 821,505 & 971,920 & 881,334 & 901,406 & 925,577 \\
\hline 6 & OSAKA & 603,567 & 655,707 & 808,968 & 723,781 & 742,248 & 765,869 \\
\hline 7 & ALEXANDRIA & 739,968 & 571,386 & 795,073 & 705,048 & 693,597 & 728,853 \\
\hline 8 & GUAYAQUIL & 511,478 & 585,778 & 780,811 & 661,637 & 687,194 & 718,394 \\
\hline 9 & SHENZEN & 451,676 & 514,913 & 682,551 & 577,702 & 599,841 & 626,951 \\
\hline 10 & SHANGHAI & 426,315 & 484,663 & 608,278 & 532,281 & 549,145 & 569,078 \\
\hline 11 & TIANJIN & 374,051 & 410,173 & 512,348 & 447,426 & 460,927 & 477,671 \\
\hline 12 & TOKYO & 328,220 & 371,249 & 494,771 & 423,355 & 438,562 & 457,877 \\
\hline 13 & HAI PHONG & 274,395 & 313,814 & 409,051 & 350,530 & 363,255 & 378,593 \\
\hline 14 & NAGOYA & 202,510 & 234,059 & 325,401 & 268,807 & 280,302 & 294,837 \\
\hline 15 & THĀNH-PHO-HO-CHÍ-MINH & 203,573 & 225,272 & 278,496 & 244,446 & 251,801 & 260,533 \\
\hline 16 & ABIDJAN & 159,191 & 187,815 & 266,455 & 219,933 & 229,823 & 242,200 \\
\hline 17 & VISAKHAPATNAM & 168,026 & 195,853 & & 221,585 & 230,787 & 241,929 \\
\hline 18 & BOSTON & 172,121 & 197,229 & & 219,865 & 227,817 & 237,474 \\
\hline 19 & NEW YORK & 162,396 & 188,821 & 208,9 & 207,126 & 214,281 & 222,466 \\
\hline 20 & ZHANJIANG & 151,165 & 166,85 & a & 180,553 & 185,755 & 191,872 \\
\hline 21 & SURAT & 134,639 & & 17 & 159,561 & 163,787 & 168,894 \\
\hline 22 & MIAMI & 114,417 & 128,00 & 164,879 & 143,039 & 147,729 & 153,592 \\
\hline 23 & GRANDE VITORIA & 103,789 & 118,4 & 158,389 & 134,366 & 139,496 & 145,891 \\
\hline 24 & KHULNA & 115,0 ) & 128,793 & 156,107 & 137,884 & 141,974 & 146,513 \\
\hline 25 & XIAMEN & 101,3 & 115,225 & 150,982 & 129,514 & 134,149 & 139,843 \\
\hline
\end{tabular}

Table 9 shows the differences between vir um and the minimum risks measured by ES (95\%), where the RCP8.5 scenario is usually he $\mathrm{m}_{\mathrm{t}}$ yimum and the RCP2.6 the minimum. These differences grow substantially over time. Tab 9 sh ws that they could be between $22.5 \%$ and $60.7 \%$ in 2100 for the cities selected. There are majo dit nonces, so it is necessary to form an opinion as to the likelihood of the scenarios. Without senar probabilities all the calculations are contingent on scenario realization. In the case New in 2100 the difference is $67.4 \%$, which translates into a substantial figure of US\$107,264 $\mathrm{m}$ lir AS. The biggest difference is found for Guangzhou, at US\$ 745,633 millions, an increase of $30.7 \%$.

Table 9: ES(95\%) Maximum and Minimum Scenario Damage (millions of US\$)

\begin{tabular}{|c|c|c|c|c|c|c|c|}
\hline \multirow[b]{2}{*}{ no. } & \multirow[b]{2}{*}{ Cities } & \multicolumn{2}{|c|}{2050} & \multicolumn{2}{|c|}{2075} & \multicolumn{2}{|c|}{2100} \\
\hline & & Max-Min & $\begin{array}{c}\% \\
\text { Max-Min }\end{array}$ & Max-Min & $\begin{array}{c}\% \\
\text { Max-Min }\end{array}$ & Max-Min & $\begin{array}{c}\% \\
\text { Max-Min }\end{array}$ \\
\hline 1 & GUANGZHOU GUANGDONG & 94,907 & $9.8 \%$ & 342,422 & $21.1 \%$ & 745,633 & $30.7 \%$ \\
\hline 2 & NEW ORLEANS & 125,430 & $15.5 \%$ & 249,764 & $20.9 \%$ & 395,231 & $24.6 \%$ \\
\hline 3 & KRUNG THEP (BANGKOK) & 73,540 & $16.3 \%$ & 259,555 & $40.7 \%$ & 537,546 & $53.8 \%$ \\
\hline 4 & MUMBAI & 90,302 & $25.9 \%$ & 142,594 & $20.0 \%$ & 224,210 & $22.5 \%$ \\
\hline 5 & KOLKATA (CALCUTTA) & 60,366 & $18.5 \%$ & 129,734 & $24.7 \%$ & 221,262 & $29.5 \%$ \\
\hline 6 & OSAKA & 53,611 & $18.0 \%$ & 120,106 & $27.1 \%$ & 205,401 & $34.0 \%$ \\
\hline 7 & ALEXANDRIA & 90,604 & $47.0 \%$ & 127,926 & $35.1 \%$ & 223,687 & $39.1 \%$ \\
\hline 8 & SHANGHAI & 41,824 & $25.9 \%$ & 122,963 & $39.9 \%$ & 269,332 & $52.7 \%$ \\
\hline 9 & GUAYAQUIL & 36,322 & $24.7 \%$ & 99,806 & $35.1 \%$ & 230,875 & $51.1 \%$ \\
\hline
\end{tabular}




\begin{tabular}{|l|l|rr|rr|rr|}
10 & TIANJIN & 18,083 & $11.2 \%$ & 102,599 & $38.1 \%$ & 181,963 & $42.7 \%$ \\
11 & TOKYO & 32,422 & $22.1 \%$ & 66,446 & $25.5 \%$ & 138,297 & $37.0 \%$ \\
12 & SHENZEN & 29,534 & $23.2 \%$ & 85,867 & $37.3 \%$ & 166,551 & $50.7 \%$ \\
13 & HAI PHONG & 27,338 & $29.9 \%$ & 70,526 & $40.2 \%$ & 134,656 & $49.1 \%$ \\
14 & THÀNH-PHO-HO-CHÍ-MINH & 14,454 & $19.7 \%$ & 38,888 & $29.2 \%$ & 122,891 & $60.7 \%$ \\
15 & BOSTON & 17,497 & $25.8 \%$ & 39,856 & $31.2 \%$ & 74,923 & $36.8 \%$ \\
16 & NEW YORK & 16,922 & $26.0 \%$ & 44,646 & $38.5 \%$ & 107,264 & $67.4 \%$ \\
17 & NAGOYA & 6,437 & $9.0 \%$ & 41,263 & $37.5 \%$ & 96,481 & $57.4 \%$ \\
18 & ZHANJIANG & 10,130 & $15.5 \%$ & 50,106 & $50.9 \%$ & 84,629 & $49.2 \%$ \\
19 & SURAT & 8,480 & $15.4 \%$ & 47,354 & $47.3 \%$ & 76,587 & $47.2 \%$ \\
20 & VISAKHAPATNAM & 17,007 & $37.4 \%$ & 27,834 & $26.4 \%$ & 53,148 & $35.2 \%$ \\
21 & ABIDJAN & 14,708 & $31.2 \%$ & 23,264 & $25.3 \%$ & 44,383 & $33.0 \%$ \\
22 & MIAMI & 10,766 & $22.6 \%$ & 27,635 & $34.8 \%$ & 50,462 & $44.1 \%$ \\
23 & FUKUOKA-KITAKYUSHU & 8,294 & $19.2 \%$ & 21,414 & $28.3 \%$ & 54,600 & $52.6 \%$ \\
24 & KHULNA & 8,269 & $19.4 \%$ & 28,754 & $42.4 \%$ & 41,059 & $35.7 \%$ \\
25 & XIAMEN & 8,917 & $22.1 \%$ & 24,964 & $36.7 \%$ & 49,606 & $48.9 \%$ \\
\hline
\end{tabular}

\subsection{Results for cities summarized by income group and continent}

The following results per income group are obtained using the World Ba k clas ific, tion of December 2016 (World Bank, 2016).

Table 10 shows the short-term expected damage in 2025 by ince ne grov $p$ and continent. Table 10 also shows the impact on US and Chinese mega-cities. It can be seen that with 16 cities, United States accounts for close to $32 \%$ of total expected damage and China with 13 cities accounts for near $22 \%$. Between them the US and China account for more than $50 \%$ of the expected damage in major coastal cities. Otbar lo er-middle income countries account for nearly $16 \%$ of total expected damage. Some of these countries may have $\mathrm{p}$ oble $\mathrm{s}$ runding investment in adaptation, and the same may happen in the case of the six cities from low income count

Table 10: 2025 Expected Damage per incon. rou and continent (millions of US\$)

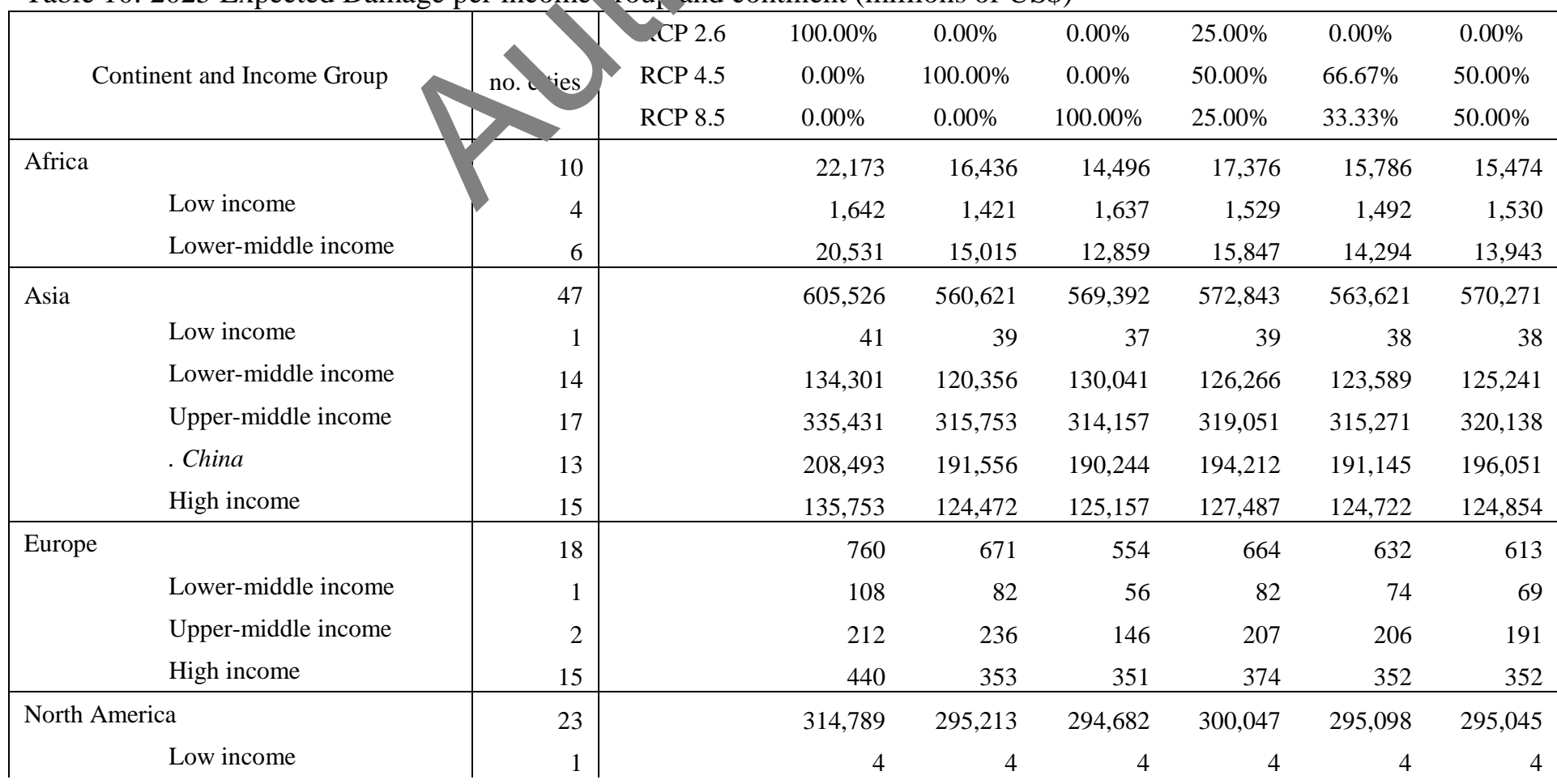




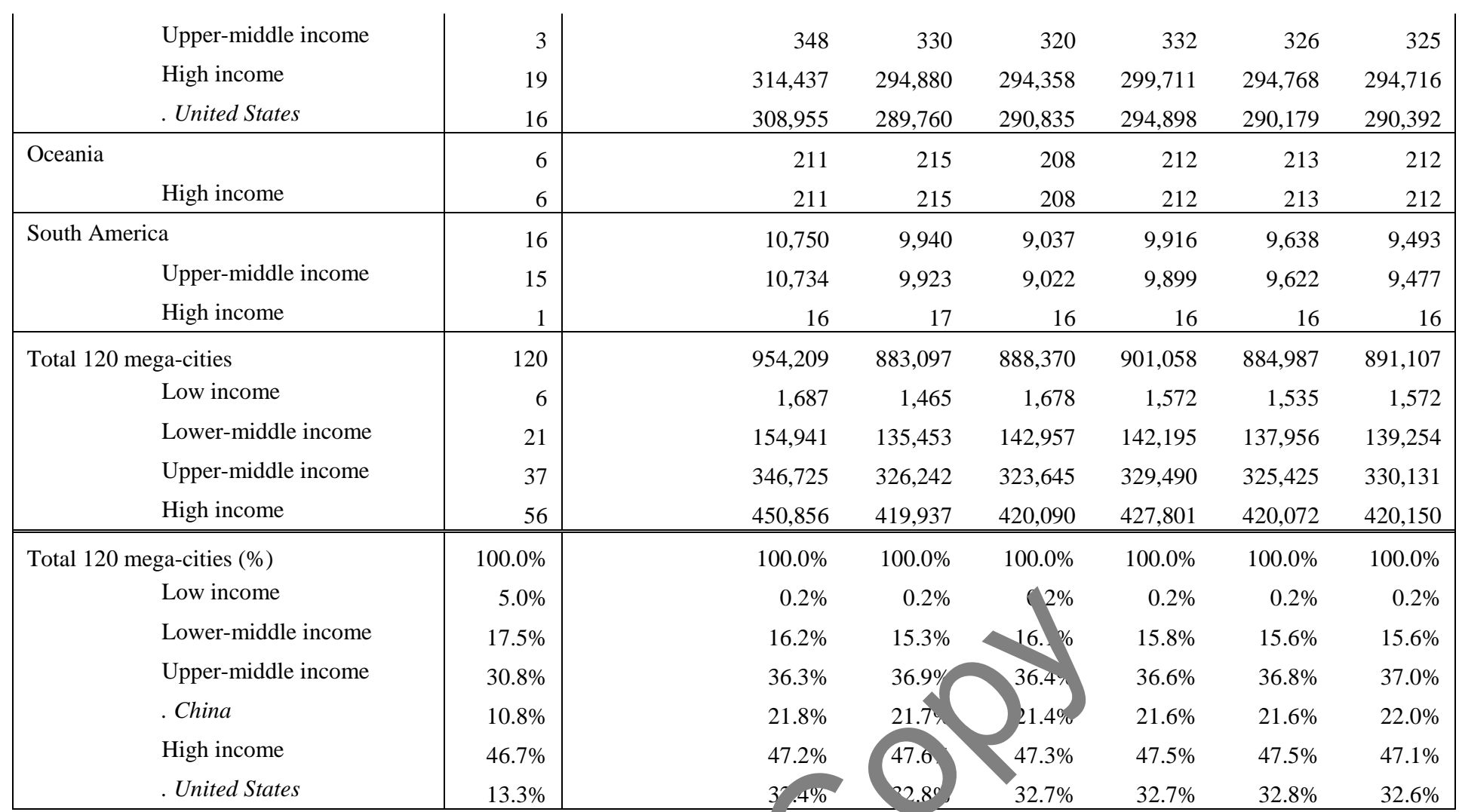

Table 11 is similar to Table 10, but shows risk measu d bv $E S(95 \%)$ on the assumption of perfect correlation between risks in cities, i.e. when the orst happens in one city the worst also happens in other cities. The United States accounts for nearly $6 \%$ and China nearly $28 \%$. This figure is lower than that for expected damage in the United Stat s bu au of its lower damage distribution volatility. By contrast the figure for $\mathrm{ES}(95 \%)$ in China is $\mathrm{h}$ oher

Lower-middle income countries acco it for nearly $20 \%$ of risk, a figure higher than that for expected damage. Asia and North America twe $\eta$ them account for $97 \%$ of the expected damage in 2025.

Table 11: 2025 Expected Shortfall ES(95\%) per nco.e group and continent (millions of US\$)

\begin{tabular}{|c|c|c|c|c|c|c|c|c|c|}
\hline \multirow{2}{*}{\multicolumn{2}{|c|}{ Continent and Income Group }} & \multirow{3}{*}{ ( } & \multirow{3}{*}{$\begin{array}{l}\mathrm{R} P 2.6 \\
\mathrm{RCP} 4.5 \\
\mathrm{RCP} 8.5\end{array}$} & \multirow{3}{*}{$\begin{array}{c}100.00 \% \\
0.00 \% \\
0.00 \% \\
\end{array}$} & \multirow{3}{*}{$\begin{array}{c}0.00 \% \\
100.00 \% \\
0.00 \% \\
\end{array}$} & \multirow{3}{*}{$\begin{array}{c}0.00 \% \\
0.00 \% \\
100.00 \% \\
\end{array}$} & \multirow{3}{*}{$\begin{array}{l}25.00 \% \\
50.00 \% \\
25.00 \% \\
\end{array}$} & \multirow{3}{*}{$\begin{array}{l}0.00 \% \\
66.67 \% \\
33.33 \% \\
\end{array}$} & \multirow{3}{*}{$\begin{array}{l}0.00 \% \\
50.00 \% \\
50.00 \% \\
\end{array}$} \\
\hline & & & & & & & & & \\
\hline \multirow{4}{*}{ Africa } & & & & & & & & & \\
\hline & & 10 & & 125,657 & 69,625 & 71,892 & 90,371 & 70,438 & 70,903 \\
\hline & Low income & 4 & & 11,356 & 10,185 & 11,662 & 10,892 & 10,710 & 10,975 \\
\hline & Lower-middle income & 6 & & 114,301 & 59,440 & 60,231 & 79,479 & 59,728 & 59,927 \\
\hline \multirow[t]{6}{*}{ Asia } & & 47 & & $1,515,173$ & $1,396,967$ & $1,441,695$ & $1,438,065$ & $1,414,473$ & $1,441,467$ \\
\hline & Low income & 1 & & 122 & 117 & 107 & 116 & 113 & 112 \\
\hline & Lower-middle income & 14 & & 366,673 & 331,284 & 365,453 & 350,803 & 344,199 & 350,305 \\
\hline & Upper-middle income & 17 & & 848,101 & 782,834 & 783,271 & 796,969 & 783,762 & 802,787 \\
\hline & . China & 13 & & 645,269 & 580,716 & 566,786 & 590,484 & 576,216 & 592,692 \\
\hline & High income & 15 & & 300,277 & 282,733 & 292,864 & 290,177 & 286,399 & 288,263 \\
\hline \multirow[t]{4}{*}{ Europe } & & 18 & & 5,553 & 5,021 & 3,721 & 4,978 & 4,662 & 4,461 \\
\hline & Lower-middle income & 1 & & 943 & 761 & 481 & 743 & 670 & 626 \\
\hline & Upper-middle income & 2 & & 2,044 & 2,573 & 1,370 & 2,243 & 2,239 & 2,050 \\
\hline & High income & 15 & & 2,565 & 1,687 & 1,869 & 1,992 & 1,752 & 1,786 \\
\hline \multicolumn{2}{|c|}{ North America } & 23 & & 571,555 & 546,151 & 585,249 & 564,291 & 561,298 & 568,343 \\
\hline
\end{tabular}




\begin{tabular}{|c|c|c|c|c|c|c|c|}
\hline Low income & 1 & 17 & 16 & 16 & 16 & 16 & 16 \\
\hline Upper-middle income & 3 & 1,069 & 1,017 & 1,054 & 1,040 & 1,029 & 1,036 \\
\hline High income & 19 & 570,469 & 545,118 & 584,178 & 563,235 & 560,252 & 567,291 \\
\hline United States & 16 & 553,754 & 529,827 & 570,919 & 547,826 & 545,446 & 552,775 \\
\hline Oceania & 6 & 750 & 716 & 723 & 727 & 718 & 720 \\
\hline High income & 6 & 750 & 716 & 723 & 727 & 718 & 720 \\
\hline South America & 16 & 41,318 & 37,252 & 35,342 & 37,951 & 36,658 & 36,388 \\
\hline Upper-middle income & 15 & 41,274 & 37,206 & 35,296 & 37,906 & 36,612 & 36,342 \\
\hline High income & 1 & 44 & 46 & 46 & 45 & 46 & 46 \\
\hline Total 120 mega-cities & 120 & $2,260,005$ & $2,055,732$ & $2,138,622$ & $2,136,384$ & $2,088,246$ & $2,122,283$ \\
\hline Low income & 6 & 11,494 & 10,317 & 11,785 & 11,024 & 10,839 & 11,103 \\
\hline Lower-middle income & 21 & 481,918 & 391,485 & 426,166 & 431,025 & 404,597 & 410,858 \\
\hline Upper-middle income & 37 & 892,489 & 823,629 & 820,991 & 838,158 & 823,643 & 842,215 \\
\hline High income & 56 & 874,104 & 830,301 & 879,681 & 856,177 & 849,168 & 858,106 \\
\hline Total 120 mega-cities (\%) & $100.0 \%$ & $100.0 \%$ & $100.0 \%$ & $100 . \%$ & $100.0 \%$ & $100.0 \%$ & $100.0 \%$ \\
\hline Low income & $5.0 \%$ & $0.5 \%$ & $0.5 \%$ & & $0.5 \%$ & $0.5 \%$ & $0.5 \%$ \\
\hline Lower-middle income & $17.5 \%$ & $21.3 \%$ & $19.0 \%$ & & $20.2 \%$ & $19.4 \%$ & $19.4 \%$ \\
\hline Upper-middle income & $30.8 \%$ & $39.5 \%$ & 40 & & $39.2 \%$ & $39.4 \%$ & $39.7 \%$ \\
\hline China & $10.8 \%$ & $28.6 \%$ & & $\%$ & $27.6 \%$ & $27.6 \%$ & $27.9 \%$ \\
\hline High income & $46.7 \%$ & 38.7 & & $41.1 \%$ & $40.1 \%$ & $40.7 \%$ & $40.4 \%$ \\
\hline United States & $13.3 \%$ & $24.5 \%$ & $253 \%$ & $26.7 \%$ & $25.6 \%$ & $26.1 \%$ & $26.0 \%$ \\
\hline
\end{tabular}

Table 12 shows the expected damage fig ces for 2050. There is a major increase in expected damage compared to the 2025 figures.

Table 12: 2050 Expected Damage per income group a $\mathrm{co}_{\text {tin }}$ nt (millions of US\$)

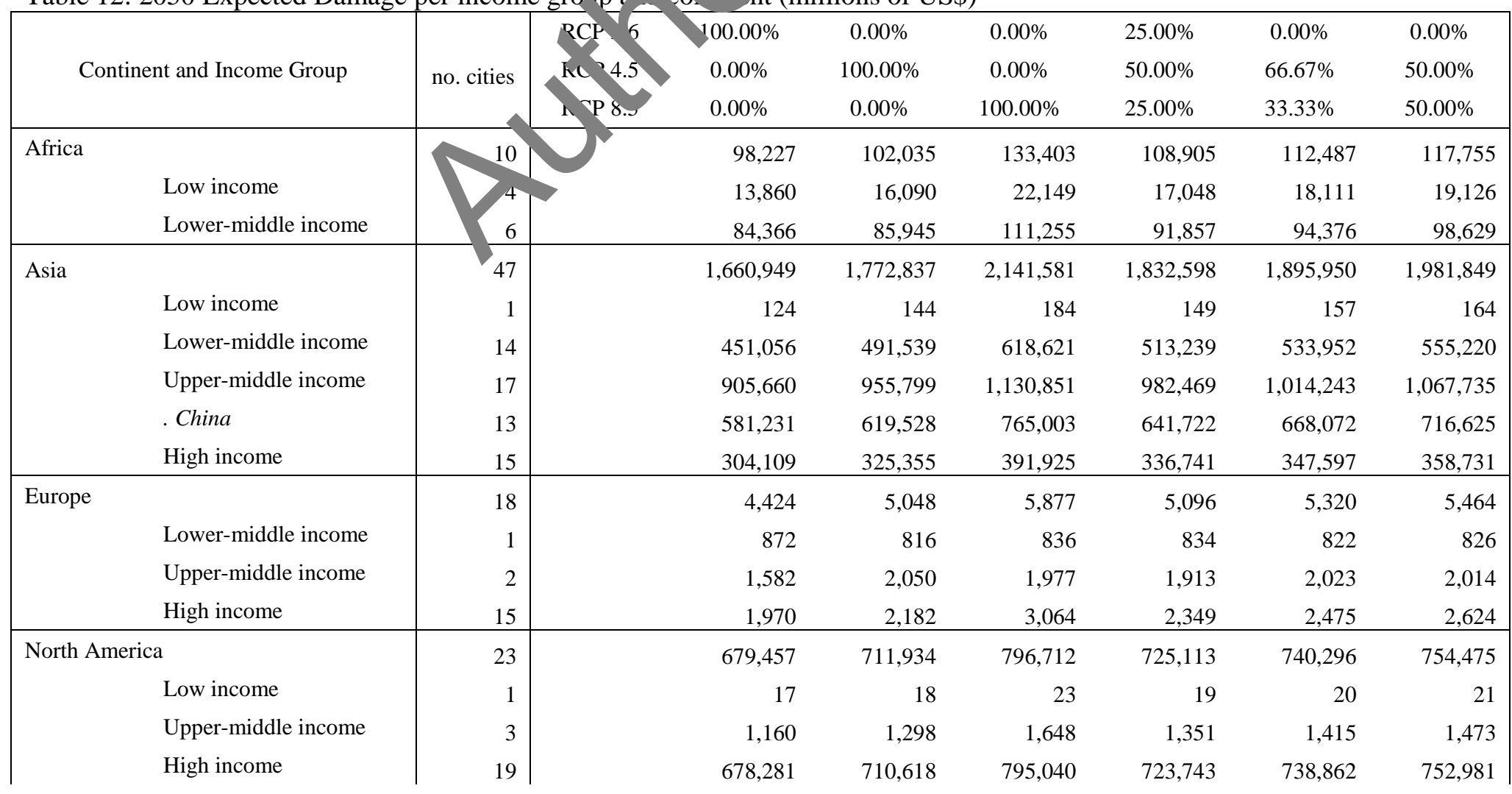




\begin{tabular}{|c|c|c|c|c|c|c|c|}
\hline United States & 16 & 662,861 & 693,575 & 775,313 & 706,433 & 720,922 & 734,591 \\
\hline Oceania & 6 & 964 & 1,209 & 1,695 & 1,269 & 1,371 & 1,452 \\
\hline High income & 6 & 964 & 1,209 & 1,695 & 1,269 & 1,371 & 1,452 \\
\hline South America & 16 & 52,564 & 61,018 & 82,742 & 64,323 & 68,248 & 71,902 \\
\hline Upper-middle income & 15 & 52,495 & 60,933 & 82,622 & 64,233 & 68,151 & 71,799 \\
\hline High income & 1 & 69 & 86 & 120 & 90 & 97 & 103 \\
\hline Total 120 mega-cities & 120 & $2,496,584$ & $2,654,081$ & $3,162,010$ & $2,737,303$ & $2,823,672$ & $2,932,897$ \\
\hline Low income & 6 & 14,000 & 16,252 & 22,356 & 17,216 & 18,288 & 19,310 \\
\hline Lower-middle income & 21 & 536,294 & 578,300 & 730,712 & 605,930 & 629,150 & 654,675 \\
\hline Upper-middle income & 37 & 960,896 & $1,020,079$ & $1,217,098$ & $1,049,965$ & $1,085,832$ & $1,143,021$ \\
\hline High income & 56 & 985,393 & $1,039,450$ & $1,191,844$ & $1,064,192$ & $1,090,402$ & $1,115,891$ \\
\hline Total 120 mega-cities (\%) & $100.0 \%$ & $100.0 \%$ & $100.0 \%$ & $100.0 \%$ & $100.0 \%$ & $100.0 \%$ & $100.0 \%$ \\
\hline Low income & $5.0 \%$ & $0.6 \%$ & $0.6 \%$ & $0.7 \%$ & $0.6 \%$ & $0.6 \%$ & $0.7 \%$ \\
\hline Lower-middle income & $17.5 \%$ & $21.5 \%$ & $21.8 \%$ & $23.1 \%$ & $22.1 \%$ & $22.3 \%$ & $22.3 \%$ \\
\hline Upper-middle income & $30.8 \%$ & $38.5 \%$ & $38.4 \%$ & $38 . \%$ & $38.4 \%$ & $38.5 \%$ & $39.0 \%$ \\
\hline China & $10.8 \%$ & $23.3 \%$ & $23.3 \%$ & & $23.4 \%$ & $23.7 \%$ & $24.4 \%$ \\
\hline High income & $46.7 \%$ & $39.5 \%$ & $39.2 \%$ & & $38.9 \%$ & $38.6 \%$ & $38.0 \%$ \\
\hline United States & $13.3 \%$ & $26.6 \%$ & $26.1 \%$ & $.5 \%$ & $25.8 \%$ & $25.5 \%$ & $25.0 \%$ \\
\hline
\end{tabular}

Table 13 shows the ES(95\%) risk figures for -000 . T ere s also a major increase in risks compared to the 2025 figures. Note that the risk can or y be sur marized if there is perfect correlation.

Table 13: 2050 Expected Shortfall ES(95\%) per income grop? and continent (millions of US\$)

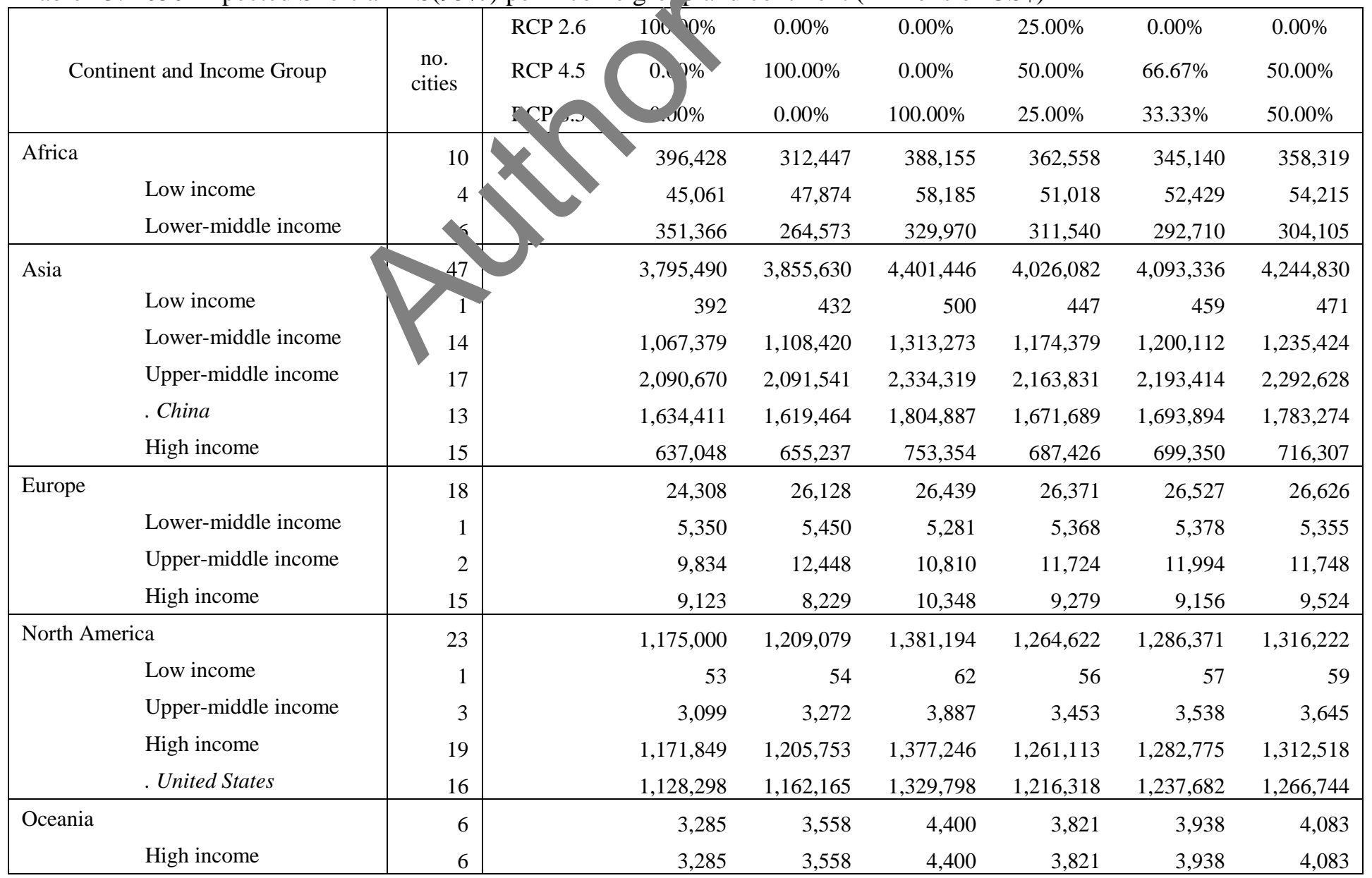




\begin{tabular}{|c|c|c|c|c|c|c|c|}
\hline South America & 16 & 200,896 & 212,623 & 253,623 & 223,874 & 229,645 & 236,784 \\
\hline Upper-middle income & 15 & 200,660 & 212,359 & 253,288 & 223,588 & 229,349 & 236,475 \\
\hline High income & 1 & 237 & 264 & 335 & 286 & 296 & 308 \\
\hline Total 120 mega-cities & 120 & $5,595,407$ & $5,619,464$ & $6,455,257$ & $5,907,329$ & $5,984,956$ & $6,186,864$ \\
\hline Low income & 6 & 45,506 & 48,360 & 58,746 & 51,521 & 52,946 & 54,744 \\
\hline Lower-middle income & 21 & $1,424,096$ & $1,378,443$ & $1,648,525$ & $1,491,287$ & $1,498,200$ & $1,544,883$ \\
\hline Upper-middle income & 37 & $2,304,263$ & $2,319,621$ & $2,602,303$ & $2,402,596$ & $2,438,295$ & $2,544,496$ \\
\hline High income & 56 & $1,821,541$ & $1,873,040$ & $2,145,683$ & $1,961,925$ & $1,995,515$ & $2,042,740$ \\
\hline Total 120 mega-cities (\%) & $100.0 \%$ & $100.0 \%$ & $100.0 \%$ & $100.0 \%$ & $100.0 \%$ & $100.0 \%$ & $100.0 \%$ \\
\hline Low income & $5.0 \%$ & $0.8 \%$ & $0.9 \%$ & $0.9 \%$ & $0.9 \%$ & $0.9 \%$ & $0.9 \%$ \\
\hline Lower-middle income & $17.5 \%$ & $25.5 \%$ & $24.5 \%$ & $25.5 \%$ & $25.2 \%$ & $25.0 \%$ & $25.0 \%$ \\
\hline Upper-middle income & $30.8 \%$ & $41.2 \%$ & $41.3 \%$ & $40.3 \%$ & $40.7 \%$ & $40.7 \%$ & $41.1 \%$ \\
\hline China & $10.8 \%$ & $29.2 \%$ & $28.8 \%$ & $28.0 \%$ & $28.3 \%$ & $28.3 \%$ & $28.8 \%$ \\
\hline High income & $46.7 \%$ & $32.6 \%$ & $33.3 \%$ & $33.2 \%$ & $33.2 \%$ & $33.3 \%$ & $33.0 \%$ \\
\hline . United States & $13.3 \%$ & $20.2 \%$ & $20.7 \%$ & 20.6 & $20.6 \%$ & $20.7 \%$ & $20.5 \%$ \\
\hline
\end{tabular}

\section{Discussion}

\subsection{Discussion of Results}

Even if mitigation policies prove extremely successful, nany cl nate impacts are already occurring and will continue to occur due to the inertia of the processe so ad ptation investments will be necessary. In this paper I calculate the expected damage and the $\mathrm{ES}(9 \mathrm{\%} \%)$ risk measures for major coastal cities around the world.

The means and above all the risks calculated ${ } \mathrm{DO}$ an relevant values for investment decision-making. Policy-makers and stakeholders need to be al are o risks and procedures need to be drawn up for jointly defining with stakeholders how muc $\mathrm{SK}$ acr city can accept. In each country and in each city there may be a different level of risk av

However, possible adaptation m sur depend on the economic possibilities of each city and country: Some low-income, lower-mirdle is ome and upper-middle income countries may find it difficult to undertake the investme need $1 \mathrm{t}$ adapt to SLR.

Without sufficient adap tir 1 masures there may be population displacement in some cities, especially in mega-cities in low-in ome and middle-income countries. International financial support may be needed by some of these chies.

The ES(95\%) risk indicator is useful and relatively easy for many stakeholders to understand. It can be compared with other figures such as city GDP as in Abadie et al. (2017). The adaptation plans of cities should be consistent with expected damage and risks and should be implemented earlier in some cities than in others.

However, flexible adaptation investment may be a good option for immediate investment decisions taking into account the risk of SLR in the coming decades, as it may avoid adaptation investment that proves unnecessary if future SLR turns out to be lower than currently expected. This option of incremental investment in the future can be achieved with an initial incremental cost, for example by building dikes with larger foundations so that the dike height can be increased in the future. These flexible adaptations may be useful if certain risks materialize, such as more melting of ice in the Arctic than expected. In the context of adaptation economics, it can be said that "Real Option Analysis quantifies the investment risk with uncertain future outcomes" (Watkiss et al., 2015). This is very useful when considering the value of flexibility of investments. "This includes the flexibility over the timing of the capital investment, but also the flexibility to adjust the investment as it progresses over time, i.e. allowing a project to adapt, expand or scale-back in response to unfolding events. The approach can 
therefore assess whether it is better to invest now or to wait - or whether it is better to invest in options that offer greater flexibility in the future." (Watkiss and Hunt, 2013), It can therefore justify options (or decisions) that would not be taken forward under a conventional economic analysis" (Watkiss and Hunt, 2013).

Determining specific adaptation measures for each city calls for an ad hoc analysis that lies outside the scope of this study. Each city will need to define its portfolio of adaptation measures considering not just hazard but also its risk aversion, geography, social and cultural values, institutional and financial resources, etc.

Nevertheless, potential measures that would need to be adapted to each city's context could include:

- Urban planning measures such as not urbanising the low-lying areas most at risk. In some cases this may necessitate reallocation of properties. Other construction measures such as building codes are also relevant.

- Protection infrastructures: improvement and building of new protection infrastructures (walls, embankments, barriers, gates, culverts, larger dikes).

- If possible, reservation of space for future adaptation infrastructures.

- Soft or behavioral measures such as early warning systems.

- Financial measures: insurance, reinsurance, bonds, etc. However, fir nncial measures may not be effective (e.g. due to insurance firms charging higher pre ium as the perceived risk becomes greater).

Each city must choose its portfolio of adaptation measures considerit. its $r$ ks and costs.

The countries with the greatest expected damage and risks in th ir $\mathrm{m}$ ga- ities are the USA and China. This is consistent with recent US history, as the last 19 years $\mathrm{s}$ ve een two of the most catastrophic coastal extreme events in the country's recent histor. In 2065 the city of New Orleans was hit by hurricane Katrina, which caused damage estimated at US\$14 billion (2010), the highest costs ever recorded for a coastal extreme event (Nicholls and Kebcue, 2012). Other direct damage included disruption of the electrical system infrastructure, hich affected up to 2.7 million people. Three nuclear plants were also affected and were forced to ry a duced level during the storm. The death of almost 1,800 people should be added to this numbe (Gra mann et al. 2005). In 2012, Hurricane Sandy killed 43 people in New York, left thousand an , caused an estimated \$US19 billion in public and private losses and crippled the financia distr t. The New York Stock Exchange closed for the first time since 1888 and the storm surge flo, ed 'w York City's subway tunnels and inundated the runways at La Guardia and Kennedy airports Ste. ${ }^{-1}$ et al., 2014).

Some cities in lower-middle $\mathrm{h}$ com countries face high risks of damage in the coming decades, and how they will fund the ea ary adaptation investments remains to be seen.

\subsection{Comparison with oth studies}

Other papers have analyze expected damage in some coastal cities, e.g. Hallegatte et al. (2013). Table 14 shows a comparison between the expected damage results obtained by Hallegatte et al. (2013) and those found in the present study. Note that the results of Hallegatte et al. (2013) are for an SLR of 20 $\mathrm{cm}$.

Table 14. Comparison of damage in 2050 with Hallegatte et al. (2013)

\begin{tabular}{|l|rrr|lr|}
\hline \multicolumn{2}{|l|}{ Expected damage costs (millions of US\$) per IPCC RCP } & \multicolumn{2}{|l|}{$\begin{array}{c}\text { Expected damage costs (millions of US\$) for an optimistic } \\
\text { sea level rise scenario from Hallegatte et al. (2013) }\end{array}$} \\
\hline Urban Agglomeration & \multicolumn{1}{|c|}{ RCP2.6 } & RCP4.5 & RCP8.5 & Urban Agglomeration & SLR 20 cm \\
\hline 1 New Orleans & 539,200 & 554,973 & 603,350 & 1 Guangzhou (S) & 254,721 \\
2 Guangzhou & 346,032 & 375,053 & 456,394 & 2 & New Orleans (S) \\
3 Krung Thep (Bangkok) & 323,092 & 334,940 & 364,059 & 3 Mumbai & 161,141 \\
4 Kolkata (Calcutta) & 198,283 & 210,923 & 235,809 & 4 Osaka (S) & 107,285 \\
5 Osaka & 180,943 & 187,319 & 213,040 & 5 Tokyo (S) & 84,968 \\
6 Mumbai & 121,190 & 132,452 & 189,435 & 6 Nagoya (S) & 61,737 \\
7 Alexandria & 67,683 & 66,586 & 84,194 & 7 Kolkata (Calcutta) (S) & 57,954 \\
& & & & & 56,303
\end{tabular}




\begin{tabular}{|c|c|c|c|c|c|}
\hline 8 Shanghai & 62,792 & 71,576 & 90,486 & 8 Tianjin (S) & 40,492 \\
\hline 9 Tokyo & 59,531 & 67,795 & 87,524 & 9 Alexandria $(\mathrm{S})$ & 34,621 \\
\hline 10 Tianjin & 56,895 & 64,084 & 77,751 & 10 Guayaquil (S) & 31,288 \\
\hline 11 Guayaquil & 37,635 & 43,459 & 58,784 & 11 Krung Thep (Bangkok) (S) & 20,778 \\
\hline 12 Zhanjiang & 29,990 & 32,569 & 37,833 & 12 Fukuoka-Kitakyushu (S) & 19,904 \\
\hline 13 Shenzen & 26,850 & 31,261 & 46,543 & 13 Vancouver (S) & 18,912 \\
\hline 14 Surat & 26,445 & 27,957 & 33,221 & 14 Shenzen & 17,553 \\
\hline 15 New York & 25,743 & 29,389 & 36,509 & 15 Zhanjiang (S) & 16,709 \\
\hline 16 Thành-Pho-Ho-Chí-Minh & 24,349 & 27,544 & 35,487 & 16 Jakarta $(\mathrm{S})$ & 16,354 \\
\hline 17 Hai Pòng & 23,077 & 27,478 & 39,758 & 17 Xiamen (S) & 12,182 \\
\hline 18 Boston & 23,059 & 26,746 & 34,725 & 18 Hiroshima (S) & 9,456 \\
\hline 19 Fukuoka-Kitakyushu & 22,334 & 23,995 & 28,496 & 19 Los Angeles-Long Beach Santa Ana & 9,427 \\
\hline 20 Houston & 18,573 & 19,225 & 21,500 & 20 Surat & 9,070 \\
\hline
\end{tabular}

* (S) indicates that the city is subject to significant subsidence.

Table 14 shows a comparison between the expected damage results obtaiped b. Hallegatte et al. (2013) and those found in present study. Note that the Hallegatte et al. (2013) mallts c for an SLR of $20 \mathrm{~cm}$. However, in my study I use the regionalized percentiles from Koph et al (2014), which incorporate specific subsidence for each city. The median SLR for Kopp et al (24 4) the three scenarios is greater than $20 \mathrm{~cm}$ in many cases, as can be seen in Table 1 . Throglu ns fo the three RCPs in Table 14 are the same as in Abadie et al. (2017).

The damage calculated in this paper, depending on the CP sce lario, varies between 1.2 and 3.7 times that found by Hallegatte at al. (2013).

Table 15 shows the mean SLR and the expected amage for the equal probability scenario, compared with Hallegatte et al. (2013).

Table 15. Comparison of damage in $\checkmark 0 \mathrm{in}$ the equal probability scenario case (millions of US\$).

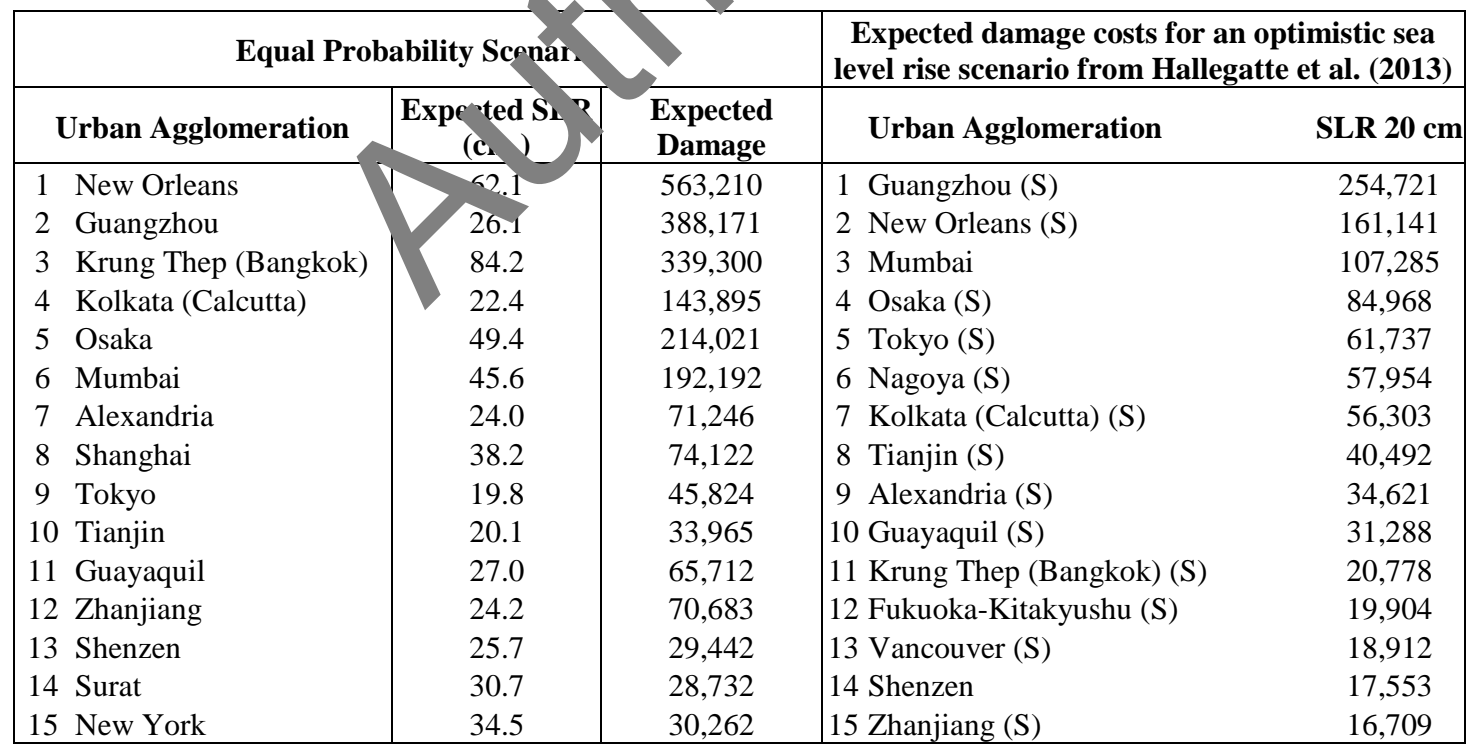

Table 15 shows the impact of a greater expected SLR in the present study. 
However, the comparison above is limited to the expected value, because calculation of risk measures as expected shortfall usually applied in financial economics is seldom applied in the evaluation of SLR risk.

Some recent papers have calculated that expected future SLR will be higher than previously estimated, e.g. Grinsted et al., (2013) and DeConto and Pollard, (2016). This justifies greater risks and expected values.

\section{Conclusions}

This work proposes a methodology for coastal adaptation decision-making using regionalized sea level rise distributions and a cost function for each city. When making decisions it is necessary to assign probabilities to the RCP scenarios. With this model the expected damage and the Expected Shortfall (ES) risk measure can be calculated. Adaptation investment decisions should be taken considering the levels of risk both before and after investment.

High levels of risk in some cities will in the future reach values un antaon to policy-makers and stakeholders, so major adaptation investment will be necessary. The inve men should be decided in advance because of the time lag in the construction of adaptation

The methodology is applied to 120 coastal mega-cities ar $d$ th wor d. The calculations highlight that there are high risk levels in some Asian and North $A$ merican crues. The study also shows that risk increases rapidly over time, and depending on each city may re ch unacceptable levels in few decades.

Some cities in lower and middle income countries may uxperience financial problems in making adaptation investments. If adaptation investments re not made in some cities, some coastal areas could experience population migrations and abando

The methodology can be useful for both ada tatio investment and city planning decision-making, for example for planning the expansion $\mathrm{f} / \mathrm{cm}$

The methodology could also be us wr more up-to-date cost function for each city. However the cost criterion used in this study is the am for all cities, which enables cities to be sorted for both expected damage and for the expected short. 'l risk measure.

\section{Appendix}

\subsection{List of abbreviations}

Table A.1: List of Abbreviations

\begin{tabular}{|l|l|}
\hline \multicolumn{1}{|c|}{ Abbreviation } & \multicolumn{1}{|c|}{ Description } \\
\hline AR5 & Fifth IPCC Assesment Report \\
DIVA & Dynamic Interactive Vulnerability Assessment \\
ES & Expected Shortfall \\
GBM & Geometric Brownian Motion \\
GDP & Gross Domestic Product \\
GEV & Generalized Extreme Value \\
GPD & Generalized Pareto Distribution \\
GSLR & Global Sea Level Rise \\
IIASA & International Institute for Applied System Analysis
\end{tabular}




\begin{tabular}{|l|l|} 
IPCC & Intergovernmental Panel on Climate Change \\
LSLR & Local Sea Level Rise \\
RCPs & Representative Concentration Pathways \\
SLR & Sea Level Rise \\
\hline
\end{tabular}

\subsection{Parameters Calculations}

I use the GBM stochastic process defined as follows:

$$
d V_{t}^{i, k}=\alpha^{i, k} V_{t}^{i, k}+\sigma^{i, k} V_{t}^{i, k} d Z_{t}^{i, k} \text { where } i \in\{1,2,3\}
$$

I calculate the parameters $\alpha^{i, k}$ and $V_{0}^{k}$ that best fit the regionalized IPCC scenarios, where $\alpha^{i, k}$ is the growth rate and $V_{0}^{k}$ is an initial value, which is the same for the three scenarios of city $k$. Note that initially I add $V_{0}^{k}$ to the median of each city in each scenario for a better fit with the three median values $(2030,2050$ and 2100).

This value $V_{0}^{k}$ grows at a rate $\alpha^{i, k}$; the term $\sigma^{i, k}$ is the instantane us volatility, and $d Z_{t}^{i, k}$ denotes the increment to a standard Wiener process. The effective sea-levo ris in city $k$ at time $t, S_{t}^{i, k}$ is then estimated as the difference between $V_{t}^{i, k}$ and $B_{0}^{i, k}$, where $B_{0}^{i, k}$ is th valu that ensures that the 2030 median is met.

$$
S_{t}^{i, k}=V_{t}^{i, k} \sim_{-i, k}^{i, k}
$$

The values of $\alpha^{i, k}$ and $X_{o}^{k}$ are estimated using quation (A.3) for median values, so the best fit is obtained by minimizing the sum on the square of the resences between the theorical value in Equation (A.3) and the median values of Kopp et (2014). The value of $\sigma^{i, k}$ is calculated by adjusting a log-normal distribution to the top percentile $25 \%$ ercentile for 2100$)$.

$$
\left.\left(\alpha^{i,}\right)-\frac{\left(\sigma^{i, k}\right)^{2}}{2}\right) t-B_{0}^{i, k}
$$

Figure A.1 shows this cal at a for New Orleans in the 8.5 scenario. The $S_{t}^{i, k}$ sea level rise median fits almost perfectly wit tho median values of Kopp et al., 2014. Note that this is now a stochastic diffusion model. The da hed line shows the fit with median values plus $V_{0}^{k}$ after the calculation of $\alpha^{i, k}$ and ${ }_{0}$ rding to Equation (A.1). Te continuous line shows the real mean values after subtracting $B_{0}^{i, k}$, ac ording to Equation (A.3), compared to the median of Kopp et al., 2014. The results show the good fit or the median for the calibrated GBM diffusion model. This model has a mean that is somewhat different from the median. 


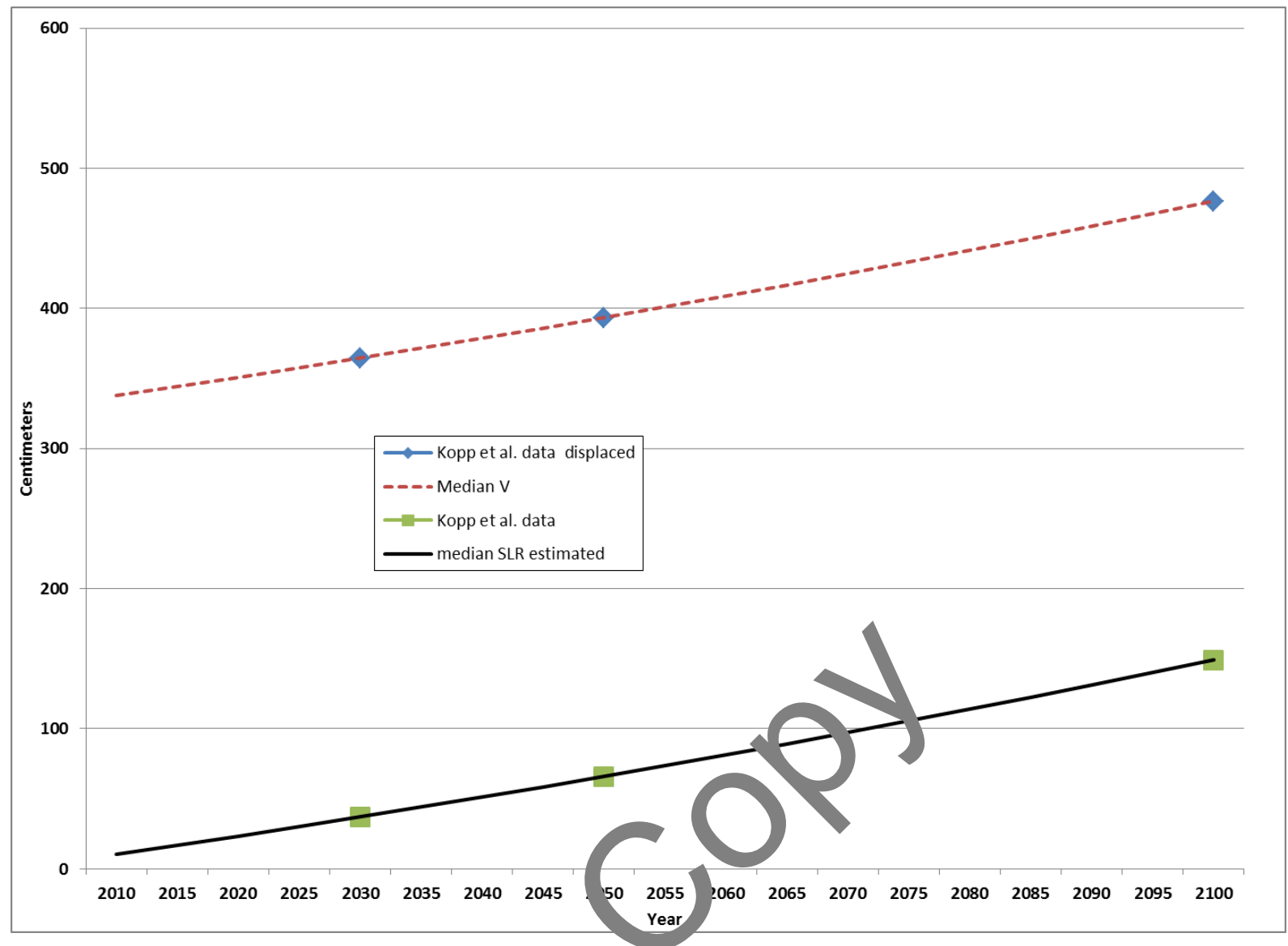

Figure A.1. Tend and initial value stochastic dif usion model estimation with median values (New Orleans $\delta$ s scenario)

At a time $t$ this distribution process generate a log normal distribution where the initial time is defined as in Equation (A.4). This is the exp t d w ' ue at the initial time of LSLR for city $k$ at future time $t$ :

$$
L_{\mathrm{G}}\left(S_{t}^{t,}=E_{0}\left(V_{t}^{i, k}\right)-B_{0}^{i, k}=V_{0}^{k} e^{\alpha^{i, k}}-B_{0}^{i, k}\right.
$$

The variance is expresed $\mathrm{I}$-scenario $i$ as in Equation (A.5).

$$
\operatorname{Var}\left(V_{t}^{i, k}\right)=\left(V_{0}^{k}\right)^{2} e^{2 \alpha^{i, k} t}\left(e^{\left(\sigma^{i, k}\right)^{2} t}-1\right)
$$
moments:

Defining $X_{t}^{i, k}=\left\{\left(V_{t}^{i, k}\right)\right.$ then $X_{t}^{i, k}$ still follows a normal distribution, with the following

$$
\begin{gathered}
E_{0}\left(X_{t}^{i, k}\right)=X_{o}^{k}+\left(\alpha^{i, k}-\frac{\left(\sigma^{i, k}\right)^{2}}{2}\right) t \\
\operatorname{Var}\left(X_{t}^{i, k}\right)=\left(\sigma^{i, k}\right)^{2} t \\
\ln \left(V_{t}^{i, k}\right): \phi\left[\ln \left(V_{0}^{k}\right)+\left(\alpha^{i, k}-\frac{\left(\sigma^{i, k}\right)^{2}}{2}\right) t,\left(\sigma^{i, k}\right)^{2} t\right]
\end{gathered}
$$

Where $X_{0}^{k}=\ln \left(V_{0}^{k}\right)$.

Table A.1 shows the parameters calculated for the stochastic diffusion process for selected cities.

Table A.1: Calibrated parameters for selected cities

\begin{tabular}{|r|c|c|cc|cc|cr|}
\hline \multirow{2}{*}{ no. } & \multirow{2}{*}{ City } & \multirow{2}{*}{$V_{0}$} & \multicolumn{2}{c|}{ RCP 2.6 } & \multicolumn{2}{c|}{ RCP 4.5 } & \multicolumn{2}{c|}{ RCP 8.5 } \\
& & & Trend & Volatility & Trend & Volatility & Trend & Volatility \\
\hline 1 & GUANGZHOU GUANGDONG & 52.69 & 0.0074 & 0.0297 & 0.0085 & 0.0275 & 0.0105 & 0.0253
\end{tabular}




\begin{tabular}{|c|c|c|c|c|c|c|c|c|}
\hline 2 & NEW ORLEANS & 333.78 & 0.0030 & 0.0053 & 0.0034 & 0.0053 & 0.0038 & 0.0063 \\
\hline 3 & MUMBAI & 36.57 & 0.0082 & 0.0250 & 0.0100 & 0.0228 & 0.0122 & 0.0226 \\
\hline 4 & KRUNG THEP (BANGKOK) & 407.19 & 0.0035 & 0.0039 & 0.0037 & 0.0040 & 0.0042 & 0.0048 \\
\hline 5 & KOLKATA (CALCUTTA) & 144.96 & 0.0053 & 0.0092 & 0.0059 & 0.0092 & 0.0067 & 0.0102 \\
\hline 6 & OSAKA & 167.14 & 0.0043 & 0.0096 & 0.0049 & 0.0096 & 0.0060 & 0.0106 \\
\hline 7 & ALEXANDRIA & 59.16 & 0.0062 & 0.0303 & 0.0071 & 0.0175 & 0.0090 & 0.0196 \\
\hline 8 & GUAYAQUIL & 31.90 & 0.0086 & 0.0278 & 0.0101 & 0.0258 & 0.0127 & 0.0244 \\
\hline 9 & SHENZEN & 29.94 & 0.0090 & 0.0319 & 0.0107 & 0.0282 & 0.0134 & 0.0263 \\
\hline 10 & SHANGHAI & 93.02 & 0.0060 & 0.0153 & 0.0069 & 0.0150 & 0.0083 & 0.0156 \\
\hline 11 & TIANJIN & 72.11 & 0.0054 & 0.0233 & 0.0067 & 0.0206 & 0.0086 & 0.0198 \\
\hline 12 & TOKYO & 56.42 & 0.0063 & 0.0223 & 0.0076 & 0.0209 & 0.0099 & 0.0211 \\
\hline 13 & HAI PHONG & 60.68 & 0.0064 & 0.0199 & 0.0075 & 0.0189 & 0.0093 & 0.0190 \\
\hline 14 & NAGOYA & 9.85 & 0.0106 & 0.0695 & 0.0144 & 0.0559 & 0.0199 & 0.0436 \\
\hline 15 & THÀNH-PHO-HO-CHÍ-MINH & 73.28 & 0.0064 & 0.0192 & 0.0073 & 0.0180 & 0.0089 & 0.0179 \\
\hline 16 & ABIDJAN & 34.27 & 0.0066 & 0.0301 & 0.0084 & 0.0272 & 0.0114 & 0.0255 \\
\hline 17 & VISAKHAPATNAM & 36.63 & 0.0079 & 0.0262 & 0.0094 & 0.0243 & 0.0116 & 0.0242 \\
\hline 18 & BOSTON & 66.91 & 0.0061 & 0.0209 & & 0.0195 & 0.0091 & 0.0202 \\
\hline 19 & NEW YORK & 73.28 & 0.0061 & 0.0189 & 0 & 0.0184 & 0.0089 & 0.0190 \\
\hline 20 & ZHANJIANG & 85.53 & 0.0058 & $0.01 \%$ & & 0.0169 & 0.0082 & 0.0167 \\
\hline 21 & SURAT & 93.02 & 0.0061 & & .0070 & 0.0144 & 0.0083 & 0.0146 \\
\hline 22 & MIAMI & 93.51 & 0.0045 & 0.014 & 0.0054 & 0.0147 & 0.0069 & 0.0152 \\
\hline 23 & GRANDE VITORIA & 65.57 & 0.0059 & 0.034 & 0.0069 & 0.0186 & 0.0088 & 0.0192 \\
\hline 24 & KHULNA & 68.46 & $0.0 \% 0$ & 0.0190 & 0.0080 & 0.0181 & 0.0093 & 0.0183 \\
\hline 25 & XIAMEN & 52.69 & 0.0070 & 0.0219 & 0.0082 & 0.0212 & 0.0104 & 0.0211 \\
\hline 26 & FUKUOKA-KITAKYUSHU & 41.43 & 0.079 & 0.0252 & 0.0092 & 0.0240 & 0.0118 & 0.0233 \\
\hline 27 & CHENNAI & & & 0.0281 & 0.0108 & 0.0263 & 0.0133 & 0.0246 \\
\hline 28 & LOMÉ & 0.0 & 0.0055 & 0.0151 & 0.0064 & 0.0147 & 0.0079 & 0.0156 \\
\hline 29 & VANCOUVER & & 0.0107 & 0.0405 & 0.0123 & 0.0349 & 0.0151 & 0.0312 \\
\hline 30 & HIROSHIMA & & 0.0060 & 0.0143 & 0.0068 & 0.0143 & 0.0083 & 0.0151 \\
\hline 31 & HOUSTON & 59.13 & 0.0046 & 0.0096 & 0.0052 & 0.0089 & 0.0060 & 0.0105 \\
\hline 32 & SAN FRANCISCO & 59.16 & 0.0064 & 0.0194 & 0.0073 & 0.0189 & 0.0090 & 0.0189 \\
\hline 33 & TAIPEI & 56.42 & 0.0066 & 0.0227 & 0.0077 & 0.0219 & 0.0099 & 0.0217 \\
\hline 34 & KOCHI (COCHIN) & 36.88 & 0.0091 & 0.0242 & 0.0104 & 0.0232 & 0.0128 & 0.0222 \\
\hline 35 & TAMPA-ST. PETERSBURG & 78.13 & 0.0056 & 0.0166 & 0.0065 & 0.0158 & 0.0080 & 0.0169 \\
\hline 36 & SAN JUAN & 50.62 & 0.0072 & 0.0209 & 0.0082 & 0.0202 & 0.0101 & 0.0201 \\
\hline 37 & HONG KONG & 41.80 & 0.0074 & 0.0266 & 0.0087 & 0.0249 & 0.0111 & 0.0236 \\
\hline 38 & WASHINGTON DC & 132.03 & 0.0038 & 0.0128 & 0.0046 & 0.0125 & 0.0057 & 0.0134 \\
\hline 39 & NINGBO & 66.91 & 0.0060 & 0.0201 & 0.0071 & 0.0191 & 0.0091 & 0.0193 \\
\hline 40 & VIRGINIA BEACH & 116.39 & 0.0047 & 0.0137 & 0.0056 & 0.0129 & 0.0067 & 0.0142 \\
\hline
\end{tabular}

\subsection{Monte Carlo Simulation}

For a GBM it is possible to find a discretization algorithm which is both exact and simple, i.e. the differential equation can be integrated exactly; the result is as follows: 


$$
V_{t}^{i, k}=V_{0}^{k} e^{\left(\alpha^{i, k}-\frac{\left(\sigma^{i, k}\right)^{2}}{2}\right) t+\sigma^{i, k}} \int_{0}^{t} d z_{i}^{i, k}
$$

Now, over a time step $\Delta t$ the following emerges:

$$
V_{t+\Delta t}^{i, k}=V_{t}^{i, k}+\Delta V_{t}^{i, k}=V_{t}^{i, k} e^{\left(\alpha^{i, k}-\frac{\left(\sigma^{i, k}\right)^{2}}{2}\right) \Delta t+\sigma^{i, k} \sqrt{\Delta t} \varepsilon}
$$

Where $\Delta V_{t}^{i, k}$ denotes the change in $V_{t}^{i, k}$ over $\Delta t$, and $\varepsilon$ stands for a random sample from a $N(0,1)$ distribution. With this simulation it is possible to obtain the SLR values using Equation A.2. This can be seen in (Abadie and Chamorro, 2013) using the Monte Carlo Method together with stochastic diffusion models.

Note that Equation (A.10) is an exact expression. Therefore, $\Delta t$ need not be small. Indeed, if there is just one risk value which depends only on the terminal value of the asset then the latter can be simulated in a great leap using a time step of length $T$. However there remains a minor error that can arise from using a finite number of random numbers.

\section{Acknowledgments}

Luis M. Abadie is grateful for financial support recei ca fron the Basque Government via project GIC12/177-IT-399-13 and the Spanish Ministry of Sci nce and 'nnovation (ECO2015-68023).

\section{References}

Abadie, L.M., Chamorro, J.M., 20, In . in theory and practice, 1 st er. Springer, London.

Abadie, L.M., Galarrag , 1., Gain zue Murieta, E., 2017. Understanding risks in the light of uncertainty: low-probability, b gh-1mpact coastal events in cities. Environmental Research Letters 12. doi:doi:10.1088/1 748-9326/aa5254

Abadie, L.M., Sainz de Murrieta, E., Galarraga, I., 2016. Climate risk assessment under uncertainty: an application to main European coastal cities. Frontiers in Marine Science 3, 1-13. doi:doi: 10.3389/fmars.2016.00265

Artzner, P., Delbaen, F., Eber, J.-M., Heath, D., 1999. Coherent Measures of Risk. Mathematical Finance 9, 203-228. doi:10.1111/1467-9965.00068

Boettle, M., Rybski, D., Kropp, J.P., 2016. Quantifying the effect of sea level rise and flood defence a point process perspective on coastal flood damage. Nat. Hazards Earth Syst. Sci. 16, 559-576. doi:10.5194/nhess-16-559-2016

Boettle, M., Rybski, D., Kropp, J.P., 2013. Adaptation to sea level rise: calculating costs and benefits for the case study Kalundborg, Denmark, in: Schmidt-Thomé, P., Klein, J. (Eds.), Climate Change Adaptation in Practice: From Strategy Development to Implementation. John Wiley \& Sons Inc, Chichester, pp. 25-34.

Chambwera, M., Heal, G., Dubeux, C., Hallegatte, S., Leclerc, L., Markandya, A., McCarl, B.A., Mechler, R., Neumann, J.E., 2014. Economics of adaptation, in: Field, C.B., Barros, V.R., Dokken, D.J., Mach, K.J., Mastrandrea, M.D., Bilir, T.E., Chatterjee, M., Ebi, K.L., Estrada, Y.O., Genova, R.C., Girma, B., Kissel, E.S., Levy, A.N., MacCracken, S., Mastrandrea, P.R., White, L.L. (Eds.), Climate Change 2014: Impacts, Adaptation, and Vulnerability. Part A: 
Global and Sectoral Aspects. Contribution of Working Group II to the Fifth Assessment Report of the Intergovernmental Panel of Climate Change. Cambridge University Press, Cambridge, United Kingdom and New York, NY, USA, pp. 945-977.

Dasgupta, S., Laplante, B., Meisner, C., Wheeler, D., Yan, J., 2009. The impact of sea level rise on developing countries: a comparative analysis. Climatic Change 93, 379-388.

DeConto, R. M., and D. Pollard (2016), Contribution of Antarctica to past and future sea-level rise, Nature, 531, 591-597, doi:10.1038/nature17145.

Editorial, 2016. The devil is in the deep tail. Nature Clim. Change 6, 431. doi:10.1038/nclimate3021

Graumann, A., Houston, T., Lawurimore, J., Levinson, D., Lott, N., McCown, S., Stephens, S., Wuertz, D., 2005, Hurricane Katrina - A Climatological Perspective, Technical Report 2005-01, National Climatic Data Center, National Oceanic and Atmospheric Administration, Washington, DC [available at https://www.ncdc.noaa.gov/oa/reports/tech-report-200501z.pdf.

Grinsted, A., J. C. Moore, and S. Jevrejeva (2013), Projected Atlantic hurricane surge threat from rising temperatures. Proc. Natl. Acad. Sci. U. S. A., 110(14), 5369-73, doi:10.1073/pnas.1209980110.

Hallegatte, S., Green, C., Nicholls, R.J., Corfee-Morlot, J., 2013. Future flood losses in major coastal cities. Nature Climate Change 3, 802-806.

Heberger, M., Cooley, H., Herrera, P., Gleick, P.H., Moore, E., 2011. Potential impacts of increased coastal flooding in California due to sea-level rise. Climatic Change 109, 229-249. doi:10.1007/s10584-011-0308-1

Hinkel, J., Jaeger, C., Nicholls, R.J., Lowe, J., Renn, O., Peijun, S., 2015 . So. vel rise scenarios and coastal risk management. Nature Clim. Change 5, 188-190. bi:10 1038 iclimate2505

Hinkel, J., Lincke, D., Vafeidis, A.T., Perrette, M., Nicholls, R.J To, R J., Marzeion, B., Fettweis, X., Ionescu, C., Levermann, A., 2014. Coastal flood d mag an adaptation costs under 21st century sea-level rise. PNAS 111, 3292-3297.

Hull, J., 2012. Options, futures, and other derivatives, th ed. ๔ . Pearson/Prentice Hall, Upper Saddle River, N.J.

Hunt, A., Watkiss, P., 2010. Climate change impacts and auaptation in cities: a review of the literature. Clim. Change 104, 13-49. doi:10.1007/s 1584-010-9975-6

IPCC, 2013. Annex II: Climate System Scep 1. Jles, in: Prather, M., Flato, D., Friedlingstein, P., Jones, C., Lamarque, J.F., Liao, H Ras h, P. (Eds.), Climate Change 2013: The Physical Science Basis. Contributio Group I to the Fifth Assessment Report of the Intergovernmental Panel on 4 imat, Change. Cambridge University Press, Cambridge (UK) and New York (USA).

IPCC, 2014. Summary for Polic mans, in: Field, C.B., Barros, V.R., Dokken, D.J., Mach, K.J., Mastrandrea, M.D., E. 'ir, T స., Chatterjee, M., Ebi, K.L., Estrada, Y.O., Genova, R.C., Girma, B., Kissel, E.S Duv, F., MacCracken, S., Mastrandrea, P.R., White, L.L. (Eds.), Climate Change 2014: 1 ar .cts, Adaptation, and Vulnerability. Part A: Global and Sectoral Aspects. Contribution of orking Group II to the Fifth Assessment Report of the Intergovernmental Panel on Climate Change. Cambridge University Press, Cambridge, United Kingdom, and New York, NY, USA, pp. 1-32.

IPCC, 2014. Climate Change 2014: Impacts, Adaptation, and Vulnerability. Part A: Global and Sectoral Aspects. Contribution of Working Group II to the Fifth Assessment Report of the Intergovernmental Panel on Climate Change. Cambridge University Press, Cambridge, United Kingdom and New York, NY, USA.

IPCC, 2013. Annex II: Climate System Scenario Tables, in: Prather, M., Flato, D., Friedlingstein, P., Jones, C., Lamarque, J.F., Liao, H., Rasch, P. (Eds.), Climate Change 2013: The Physical Science Basis. Contribution of Working Group I to the Fifth Assessment Report of the Intergovernmental Panel on Climate Change. Cambridge University Press, Cambridge (UK) and New York (USA).

Kontogianni, A., Tourkolias, C.H., Damigos, D., Skourtos, M., 2014. Assessing sea level rise costs and adaptation benefits under uncertainty in Greece. Environ. Sci. Policy 37, 61-78. doi:10.1016/j.envsci.2013.08.006

Kopp, R.E., Horton, R.M., Little, C.M., Mitrovica, J.X., Oppenheimer, M., Rasmussen, D.J., Strauss, B.H., Tebaldi, C., 2014. Probabilistic 21st and 22nd century sea-level projections at a global 
network of tide-gauge sites: KOPP ET AL. Earth's Future 2, 383-406. doi:10.1002/2014EF000239

Nicholls, R.J., Kebede, A.S., 2012. Indirect impacts of coastal climate change and sea-level rise: the UK example. Climate Policy 12, S28-S52.

Nordhaus, W.D., 2011. The Economics of Tail Events with an Application to Climate Change. Rev Environ Econ Policy 5, 240-257. doi:10.1093/reep/rer004

Pindyck, R.S., 2011. Fat Tails, Thin Tails, and Climate Change Policy. Rev Environ Econ Policy 5, 258-274. doi:10.1093/reep/rer005

Rockafellar, R.T., Uryasev, S., 2002. Conditional value-at-risk for general loss distributions. Journal of Banking \& Finance 26, 1443-1471. doi:10.1016/S0378-4266(02)00271-6

Steffen, W., Hunter, J., Hughes, L., 2014. Counting the Costs: Climate Change and Coastal Flooding. Climate Council of Australia Ltd, Australia.

Watkiss, P., Hunt, A., 2013. Real Options Analysis: Decision Support Methods for Adaptation (No. Briefing Note 4), MEDIATION Project. Funded by the EC's 7FWP.

Watkiss, P., Hunt, A., Blyth, W., Dyszynski, J., 2015. The use of new economic decision support tools for adaptation assessment: A review of methods and applications, towards guidance on applicability. Climatic Change 132, 401-416. doi:10.1007/s10584-014-1250-9

Weitzman, M.L., 2013. A Precautionary Tale of Uncertain Tail Fattening. Er viron Resource Econ 55, 159-173. doi:10.1007/s10640-013-9646-y

Weitzman, M.L., 2009. On Modeling and Interpreting the Economics of Catan phic Climate Change. Review of Economics and Statistics 91, 1-19. doi:10.1162/re t.91. 1

Weitzman, M.L., 2007. A review of the Stern Review on the econom c climate change. Journal of Economic Literature 45, 703-724.

Woodward, M., Gouldby, B., Kapelan, Z., Khu, S.-T. rownen I 2011. Real Options in flood risk management decision making. J. Flood R sk Mar g. 4, 339-349. doi:10.1111/j.1753318X.2011.01119.

Wilmott, P., 2014. Paul wilmott on quantitative finance. Wney, Hoboken, N.J.

World Bank Country and Lending Groups 2016

https://datahelpdesk.worldbank.org/k lec. ebase/articles/906519-world-bank-country-andlending-groups. Acceded 3/21/2017 